Article

\title{
Simulation of Forestland Dynamics in a Typical Deforestation and Afforestation Area under Climate Scenarios
}

\author{
Qun'ou Jiang 1,2,3,4,*, Yuwei Cheng ${ }^{1}$, Qiutong Jin ${ }^{1}$, Xiangzheng Deng ${ }^{3,4}$ and Yuanjing Qi ${ }^{1,2, *}$ \\ 1 School of Soil and Water Conservation, Beijing Forestry University, Beijing 100038, China; \\ E-Mails: chengyw2012@gmail.com (Y.C.); jinqiutong@bjfu.edu.cn (Q.J.) \\ 2 Key Laboratory of Soil and Water Conservation \& Desertification Combat, Beijing Forest University, \\ Beijing 100038, China \\ 3 Institute of Geographic Sciences and Natural Resources Research, Chinese Academy of Sciences, \\ Beijing 100101, China; E-Mail: dengxz.ccap@igsnrr.ac.cn \\ 4 Center for Chinese Agricultural Policy, Chinese Academy of Sciences, Beijing 100101, China \\ * Authors to whom correspondence should be addressed; \\ E-Mails: jiangqo.dls@163.com (Q.J.); qiyuanjing0506@163.com (Y.Q.); \\ Tel.: +86-10-6233-6614 (Q.J. \& Y.Q.).
}

Academic Editor: Jinwei Dong

Received: 30 June 2015 / Accepted: 15 September 2015 / Published: 24 September 2015

\begin{abstract}
Forestland dynamics can affect the ecological security of a country and even the global environment, and therefore it is of great practical significance to understand the characteristics of temporal and spatial variations of forestland. Taking Jiangxi Province as the study area, this study first explored the driving mechanism of the natural environment and social economy on deforestation and afforestation using a simultaneous equation model. The results indicate that population size, topographic and geomorphologic factors, climate, and location play leading roles in influencing forestland density fluctuations. Specifically, the population size, economic development level, gross value of forestry production, climate conditions, and government policies are key influencing factors of afforestation. Deforestation is mainly influenced by agricultural population, non-agricultural economy, forestry production, forestry density, location, transportation, and climate. In addition, this study simulated the spatial distribution of land use and analyzed the spatial characteristics and variation trends of forestland area and quality under the Representative Concentration Pathways (RCPs) climate scenarios from 2010 to 2030 using the Conversion of Land Use and its Effects (CLUE) model. The results indicate that forestland declines
\end{abstract}


under the Asia-Pacific integrated model (AIM) climate scenario. The environment tends to be heavily damaged under this kind of scenarios, and measures should be taken in order to protect the environment. Although the model for energy supply strategy alternatives and their general environmental impact (MESSAGE) scenario is to some extent better than the AIM scenario, destruction of the environment will still occur, and it is necessary to restrain deforestation and convert shrub land into forestland or garden land. These results can provide significant information for environmental protection, forest resource exploitation, and utilization in the areas experiencing deforestation and afforestation.

Keywords: dynamics of forestland; driving mechanism; climate scenario; simulation

\section{Introduction}

Humanity is facing various effects brought by climate change, which is currently a hotspot of geographical science research, with increasing impacts on the physical environment as the progress of human society continues [1-8]. Climate change is mainly affected by natural factors and human activities, among which land use change plays a significant role. As a major type of land use, forestland plays a key role in improving the environment, maintaining the global carbon balance, conserving biodiversity, and conserving soil and water, etc. Besides, to increase carbon sinks and alleviate climate change, it is necessary to expand forestland area and increase the forest volume worldwide. In addition, forestland even serves as the foundation for the survival and development of humans and other organisms, and therefore forestland dynamics is not only a major subject of global change research but also a key indicator of global change [9-17]. It is necessary to comprehend the causes and process of the temporal and spatial variation of forestland, and analyzing the forestland dynamics, understanding the spatial and temporal distribution of forest changes, and rationally protecting forestland have currently become important issues in the world.

Deforestation and afforestation have constantly occurred in China during the past decades for a number of reasons, such as the increasing demand for the forest products, changes of national policies, and implementation of the Grain for Green Project and other afforestation projects. There were substantial fluctuations in the total forestland area in China during the period 1985-2005 [18-27]. Firstly, forestland area increased by $2.23 \times 10^{6} \mathrm{hm}^{2}$ due to the shrub and woodland expansion in the 1980s. Then, a large amount of woodland was destroyed in the 1990s, and later the forestland area recovered due to the implementation of the Grain for Green Project. In addition, the gradual improvement of people's living standards with the continuous socioeconomic development led to the requirement of a high-quality environment and higher requirements for forestry development [28-38]. Climate change is one of the significant factors that influence forestland dynamics other than human activities, and it is necessary to understand the causes and processes of spatial and temporal variation in forestland and predict their changes under different future climate scenarios, which is of significance for the rational use of forest resources and sustainable ecological, economic, and social development.

The relationship between land use change and climate change is extremely complex, and it is now widely recognized that there are some impacts of climate change on land use; however, the feedback of 
land use change on climate change is also of significance, which needs to be further studied. Yan et al. [39] analyzed the land use dynamics in the Poyang Lake area during the period 1985-2035 under four climate change scenarios, i.e., A1B, A2, B1, and no climate change, and explored the effects of climate change on land use change in the Poyang Lake area in the future. Zhang [40] assessed the potential impacts of climate change on the main tree species for plantation and spatial distribution of natural vegetation in China under the A2 climate scenario. Little research has been conducted on forestland dynamics under the climate scenarios of the Fifth Assessment Report published by the IPCC. In the fifth assessment report in 2014, the IPCC introduced a set of scenarios according to atmospheric radiation intensity, known as the Representative Concentration Pathways (RCPs) [21,23-25]. The newly assigned scenarios start from a more scientific and applicable approach, and therefore this study will explore forestland dynamics under the RCPs climate scenario according to the newly published criteria in the fifth assessment report. The study of the spatial and temporal dynamic processes of deforestation and afforestation under RCPs climate scenarios can provide important scientific evidence for sustainable forestry development and macroeconomic policy-making [41-47].

This study will reveal the temporal and spatial variation in forestland under future scenarios through simulation and prediction of deforestation and afforestation dynamics using the Conversion of Land Use and its Effects (CLUE) model. The case study area is introduced in Section 2, and the data sources, methodology, and scenario design are provided in Section 3. Next, the driving mechanism will be analyzed in Section 4, and the simulation results under the climate scenario are presented in Section 5. The final part summarized the conclusions and policy recommendations.

\section{Study Area}

Jiangxi Province is a typical example of an area experiencing deforestation and afforestation in China, and serves as the study area for this research. It is located in southeast China and at the middle and lower reaches of the Yangtze River (Figure 1). Specifically, it is located between $24^{\circ} 29^{\prime} 14^{\prime \prime}-30^{\circ} 04^{\prime} 41^{\prime \prime} \mathrm{N}$ and $113^{\circ} 34^{\prime} 36^{\prime \prime}-118^{\circ} 28^{\prime} 58^{\prime \prime} \mathrm{E}$. The climate of this area is moderate and moist, with an annual average temperature of $18{ }^{\circ} \mathrm{C}$ and an annual average precipitation of $1637.9 \mathrm{~mm}$. Jiangxi Province is a large basin that is inclined towards Poyang Lake and open in the north, bounded by mountains to the east, west, and south, with the north part composed of plains and the middle part composed of hills. With relatively diverse and complete geomorphology distributed irregularly as a cyclic structure, the major landforms are mountains and hills. Forestland and cultivated land are the two major types of land use in this area, accounting for nearly $90 \%$ of the total land area. The proportion of forestland area is up to $60 \%$, and cultivated land comes second, taking up $27.02 \%$. The conflict between forestland and cultivated land has been a historical problem, with urbanization, industrialization, and agricultural modernization aggravating the situation. Thus, the conflict mainly lies in the competition between cultivated land, forestland, and built-up areas. Since 1998, forestland area and forest inventory have increased due to the policy implementation of Grain for Green Project. 


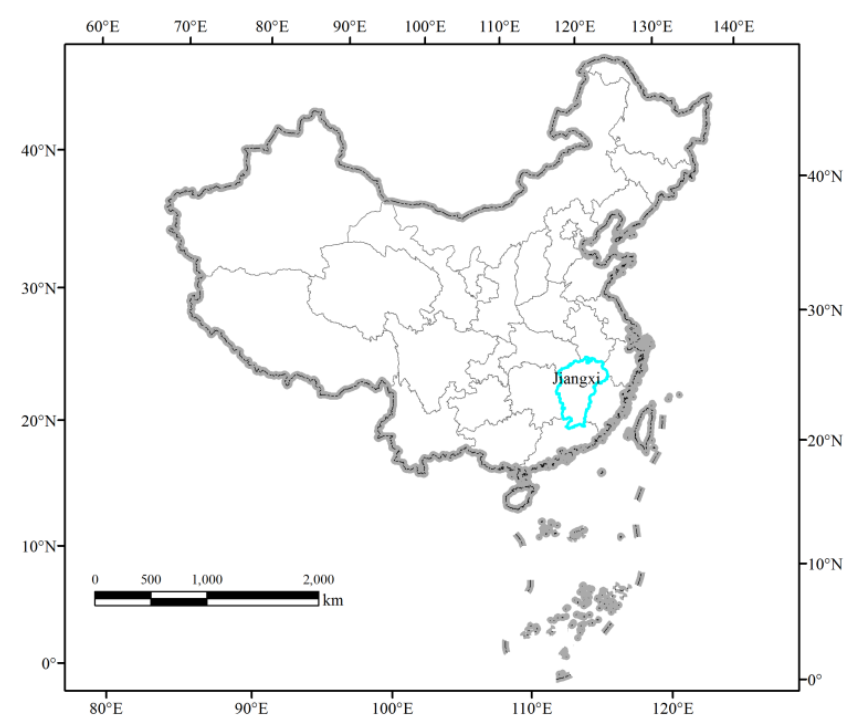

Figure 1. Location of the typical deforestation and afforestation area.

\section{Data and Methodology}

\subsection{Data Sources}

The land use data are interpreted from the remote sensing images of Landsat by the Resource and Environmental Science Data Center of the Chinese Academy of Science at a scale of 1:100,000, and its interpretation accuracy is as high as $92.7 \%$ according to the field investigation. Five types of land use are included, i.e., cultivated land, forestland, water area, built-up area, and unused land. Forestland is further divided into closed forest, open forest, shrub land, and garden areas. The 1-km area percentage data for forestland in 1988, 1995, 2000, and 2005 are produced using a 1-km area percentage data model. On this basis, this study calculates the converted area of all types during these three periods (1988-1995, 1995-2000, and 2000-2005) and lists the converted area from forestland to other land uses and from other land uses to forestland.

The natural environment is significant for forestland dynamics in Jiangxi Province, and the natural environmental data can be categorized into topography, soil properties, and meteorological data. Topography includes elevation, topographic slope, and plain area proportion. Elevation is obtained based on a Digital Elevation Model, whereas topographic slope and plain area proportion are derived from 1:250,000 DEM data in Jiangxi Province. For the soil properties, the data are derived from the second soil survey for the whole country. With respect to the meteorological data, the average annual temperature and average annual precipitation during the period 1988-2005, which are related to regional ecological processes, are derived from the data center of the national Meteorological Administration, and they are interpolated at a $1 \mathrm{~km} \times 1 \mathrm{~km}$ grid scale using the gradient plus inverse distance squares method.

Location and transportation conditions can represent the effects of human activity on forestland dynamics. The location data refer to the distance between each grid and the provincial capital, port, or the nearest road. Thus, the location data are estimated based on the spatial distribution map of the provincial capital, port and road networks. The road density is calculated on the basis of a 1:250,000 topographic map of Jiangxi Province, with the length of traffic line dividing the land area of each county. 
Socioeconomic data are also essential for forestland dynamics and land use conversion, which includes population density, agricultural population, GDP, GDP in non-agricultural industries, whether the county is a major grain-producing area, whether the county is poor, forestry production, and forestry output value. The original data are from the investigation and statistical yearbook of each county. The policy variables involved in this study also have effects on the forestland dynamics, such as the Grain for Green Project, which has been implemented at the national level and protects the environment from deforestation and afforestation to a certain extent.

Different types of forestland dynamics have various drivers, and this study selects different variables for three equations according to the local situation in Jiangxi Province to explore the driving mechanism of the forestland dynamics, and then chooses significant factors for the CLUE model (Table 1).

Table 1. Variables in the driving mechanism analysis in a typical deforestation and afforestation area.

\begin{tabular}{|c|c|c|c|}
\hline Equation & Meaning & Variables & Unit \\
\hline (1) and (2) & Population density & Popden & person $/ \mathrm{km}^{2}$ \\
\hline (3) & Population & Pop & Person \\
\hline (2) and (3) & Agricultural population, one-period lag term & Agrpop & Person \\
\hline \multirow{2}{*}{ (1) and (2) } & GDP & $\ln (g d p)$ & Million yuan \\
\hline & GDP in non-agricultural industry & $\ln ($ nagr_gdp) & Million yuan \\
\hline (1) and (3) & elevation & $\ln (d e m)$ & $\mathrm{m}$ \\
\hline (1) & Quadratic term of elevation & $(\ln (\operatorname{dem}))^{2}$ & $\mathrm{~m}$ \\
\hline (3) & Slope & $\ln ($ slope $)$ & Degree \\
\hline (3) & Quadratic term of slope & $(\ln (\text { slope }))^{2}$ & Degree \\
\hline (1) and (3) & Soil organic matter & $\ln ($ organic $)$ & - \\
\hline$(1)-(3)$ & Precipitation & $\ln (p a)$ & $\mathrm{mm}$ \\
\hline (1) and (2) & Quadratic term of precipitation & $(\ln (p a))^{2}$ & $\mathrm{~mm}$ \\
\hline$(1)-(3)$ & Air temperature & $\ln (t a)$ & Degree \\
\hline (1) and (2) & Quadratic term of air temperature & $(\ln (t a))^{2}$ & Degree \\
\hline (1) and (3) & Distance to provincial capital & $\ln (d 2 p v c p)$ & $\mathrm{km}$ \\
\hline (1) & Distance to port & $\ln (d 2 p o r t)$ & $\mathrm{km}$ \\
\hline$(1)-(3)$ & Distance to the nearest road & $\ln ($ d2road $)$ & $\mathrm{km}$ \\
\hline \multirow{2}{*}{ (1) and (3) } & Road density & $\ln ($ road_den $)$ & $\mathrm{km} / \mathrm{km}^{2}$ \\
\hline & Forestland & $\ln (Y)$ & $\mathrm{km}^{2}$ \\
\hline$(1)-(3)$ & Forestry production & $\ln \left(\mathrm{fe} \_\right.$prod $)$ & Million Yuan \\
\hline (1)-(3) & Forestry output value & $\ln \left(f e \_g d p\right)$ & Million Yuan \\
\hline (3) & Whether the county is poor & Poverty & - \\
\hline (1) and (3) & Whether the county is the major grain producing area & Grain & - \\
\hline (1) & $\begin{array}{l}\text { Whether the county is involved in the Stated-owned Forest } \\
\text { Farms and Nursery System }\end{array}$ & Mng & - \\
\hline (2) & Area of other land converted to forest land & $\ln ($ wother 20$)$ & $\mathrm{km}^{2}$ \\
\hline (3) & Area of forest land converted to other land & $\ln ($ lw20other $)$ & $\mathrm{km}^{2}$ \\
\hline (2) & Whether the county has implemented Grain for Green & $T g h l$ & - \\
\hline$(1)-(3)$ & Forestry coverage rate & $Y$ & $\%$ \\
\hline (2) and (3) & Quadratic term of forestry coverage rate & $(Y)^{2}$ & \\
\hline
\end{tabular}




\subsection{Methodology}

\subsubsection{Driving Mechanism Method}

This study analyzed the driving mechanisms for change in forestland areas via deforestation and afforestation using a model that simultaneously uses multiple equations, and Ordinary Least Squares was adopted in the model with no instrument variables. Through econometric analysis, this study explored the effects of the natural environment and social economy on forestland dynamics in deforestation and afforestation areas. This model included three equations: (1) forestland density; (2) conversion from forestland to other land use types; and (3) conversion from other types to forestland. The first equation is used to indicate the growth state of forestland in deforestation and afforestation areas, the second reflects the process of deforestation, and the third suggests a process for the protection and recovery of forestland:

$$
\begin{aligned}
& Y_{i t}=\propto_{0}+\propto_{1} \ln \left(\text { popden }_{i t-1}\right)+\propto_{2} \ln \left(g d p_{i t-1}\right) \\
& +\propto_{3} \ln \left(\text { fe_prod }_{i t-1}\right)+\propto_{4} \ln \left(f e_{-} g d p_{i t-1}\right)+\propto_{4} \ln \left(\text { dem }_{i}\right) \\
& +\propto_{5}\left(\ln \left(\text { dem }_{i}\right)\right)^{2}+\propto_{6} \ln \left(\text { organic }_{i t}\right)+\propto_{7} \ln \left(t a_{i t}\right)+\propto_{8}\left(\ln \left(t a_{i t}\right)\right)^{2} \\
& +\propto_{9} \ln \left(p a_{i t}\right)+\propto_{10}\left(\ln \left(p a_{i t}\right)\right)^{2}+\propto_{11} \ln \left(\text { road_den }_{i t-1}\right) \\
& +\propto_{12} \ln \left(d 2 \text { pvcp }_{i}\right)+\propto_{13} \ln \left(\text { d2road }_{i t}\right)+\propto_{14} \text { Grain }_{i t}+\propto_{15} \text { Mng }_{i t-1} \\
& +\varepsilon_{i t} \\
& O Y_{i t}=\beta_{0}+\beta_{1} \ln \left(\text { popden }_{i t-1}\right)+\beta_{2} \ln \left(\text { agrpop }_{i t}\right)+\beta_{3} \ln \left(g d p_{i t-1}\right) \\
& +\beta_{4} \ln \left(\text { fe_prod }_{i t-1}\right)+\beta_{5} \ln \left(f e_{-} g d p_{i t-1}\right)+\beta_{6} \ln \left(Y_{i t-1}\right) \\
& +\beta_{7}\left(\ln \left(Y_{i t-1}\right)\right)^{2}+\beta_{8} \ln \left(t a_{i t}\right)+\beta_{9}\left(\ln \left(t a_{i t}\right)\right)^{2}+\beta_{10} \ln \left(p a_{i t}\right) \\
& +\beta_{11}\left(\ln \left(p a_{i t}\right)\right)^{2}+\beta_{12} t g h l+e_{i t} \\
& S Y_{i t}=\rho_{0}+\rho_{1} \ln \left(\text { pop }_{i t-1}\right)+\rho_{2} \ln \left(\text { agrpop }_{i t-1}\right)+\rho_{3} \ln \left(\text { fe_prod }_{i t-1}\right) \\
& +\rho_{4} \ln \left(f e_{-} g d p_{i t-1}\right)+\rho_{5} \ln \left(Y_{i t-1}\right)+\rho_{6}\left(\ln \left(Y_{i t-1}\right)\right)^{2}+\rho_{7} \ln \left(\text { dem }_{i}\right) \\
& +\rho_{8} \ln \left(\text { slope }_{i}\right)+\rho_{9} \ln \left(\text { organic }_{i t}\right)+\rho_{10} \ln \left(t a_{i t}\right)+\rho_{11} \ln \left(p a_{i t}\right) \\
& +\rho_{12} \ln \left(\text { road_den }_{i t-1}\right)+\rho_{13} \ln \left(\text { d2pvcp }_{i}\right)+\rho_{14} \ln \left(\text { d2road }_{i t}\right) \\
& +\rho_{15} \text { Grain }_{i t-1}+\rho_{16} \text { Poverty }_{i t-1}+\delta_{i t}
\end{aligned}
$$

In the equation, $i$ stands for the basic unit of analysis; $t$ stands for year (1988-2005); $t-1$ means one lagging unit of $t$ (this is replaced by the average value of this variable for the last three years); $Y_{i t}$ stands for forestland density; $O Y_{i t}$ is converted area from other types to forestland; $S Y_{i t}$ is the converted area from forestland to other types; and $\varepsilon_{i t}, e_{i t}$, and $\delta_{i t}$ are random errors.

\subsubsection{Conversion of Land Use and its Effects (CLUE) Model}

The CLUE model is suitable for land use dynamics simulation in large-scale areas and has been demonstrated to be very robust [30,31]. The CLUE model mainly consists of two modules, i.e., spatial allocation and non-spatial prediction [1,2,18-20]. Specifically, the non-spatial module mainly contains the land use demand, which can be estimated using gray system prediction, system dynamics models, and socioeconomic methods, or even by directly referring to the results of land use planning and social and economic planning in the study area. The spatial module allocates the demand value to each grid 
year by year to spatially and temporally simulate the dynamics of land use based on the driving mechanisms and spatial allocation rules for land use. Therefore, driving mechanism analysis and spatial allocation rules should be made before the spatial simulation (Figure 2). The driving mechanism analysis presents the spatial relationship between the land use distribution and driving factors, and explores the effects of key driving factors on land use distribution. This spatial allocation is achieved on the basis of the empirical analysis of land use, spatial variation analysis, and dynamic simulation, and the allocation rules have been fixed in the model. Moreover, this model has been widely used in land use simulation; for more details, please refer to Verburg [30].

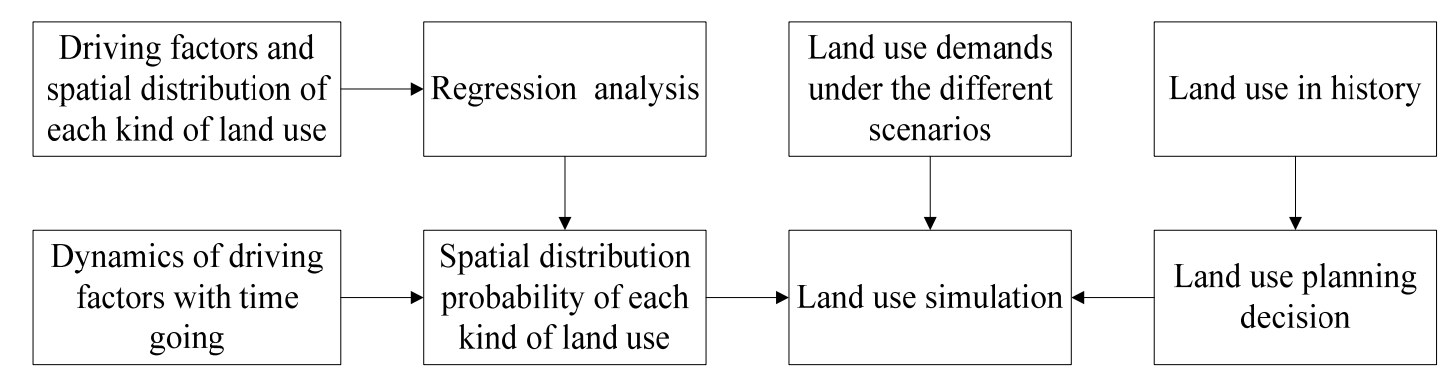

Figure 2. Flow chart of the conversion of Land Use and its Effects (CLUE) model.

\subsubsection{Scenario Design}

The RCPs scenarios are four greenhouse gas concentration trajectories adopted by the IPCC for its Fifth Assessment Report (AR5) in 2014, which describes four possible climate futures, including the model for energy supply strategy alternatives and their general environmental impact (MESSAGE), AIM, GCM, and IMAGE models. This study only takes into account the MESSAGE and AIM models, which represent the possible status of the study area and China $[25,26]$. The $0.5^{\circ} \times 0.5^{\circ}$ land use data under two climate scenarios were downloaded from the IPCC official website, which lists the percentage of each type of land use type in the $0.5^{\circ} \times 0.5^{\circ}$ grid. Then, the boundary of the study area was overlaid with the land use data, and the total area of each type of land use was calculated according to the land demand under the two climate scenarios. Finally, the land use demand data were put in the CLUE model to allocate the land use demand in a $1 \mathrm{~km}$ grid.

\subsubsection{Model for Energy Supply Strategy Alternatives and their General Environmental Impact (MESSAGE) Climate Scenario}

The MESSAGE model, also called model for energy supply strategy alternatives and their general environmental impact, is a high RCP scenario (RCP8.5). The atmospheric radiation intensity under the MESSAGE scenario will increase to more than $8.5 \mathrm{~W} \cdot \mathrm{m}^{-2}$, which suggests that there is no net reduction in the global scale. This climate model can provide the latest scenario, which is similar to the revised A2 scenario. Therefore, it is possible to compare with early climate assessments, which can help maintain the continuity of climate assessment from the perspective of climate simulation. This scenario takes population, expected future GDP, efficiency improvement, and energy consumption into account, and the emissions in developed and developing countries will increase to various degrees, with increases of $84 \%$ and 3.8 times by 2100 , respectively. 
Under the MESSAGE climate scenario, cultivated land increases rapidly. However, the speed of growth slows down after 2020, and in 2030, the cultivated land will have increased by $3.3 \%$ compared with 2005 (Figure 3). In contrast, the areas of forestland and grassland drop dramatically during the period 2005-2030. Among them, the forestland area drops $0.1 \%$ annually, which is higher than the reduction rate under the AIM climate scenario. Although fluctuations in the reduction rate between years still exist, its range remains relatively stable. The changing rate of grassland between 2005 and 2010 is relatively small, but in the following period, between 2010 and 2020, the reduction rate increases substantially. After 2020, the rate of change decreases again. The grassland will have decreased by $15.5 \%$ in 2030 compared with 2005 . The built-up area, on the other hand, increases rapidly and stably during the study period. The annual growth rate is two or three times that of the rate under the AIM climate scenario.
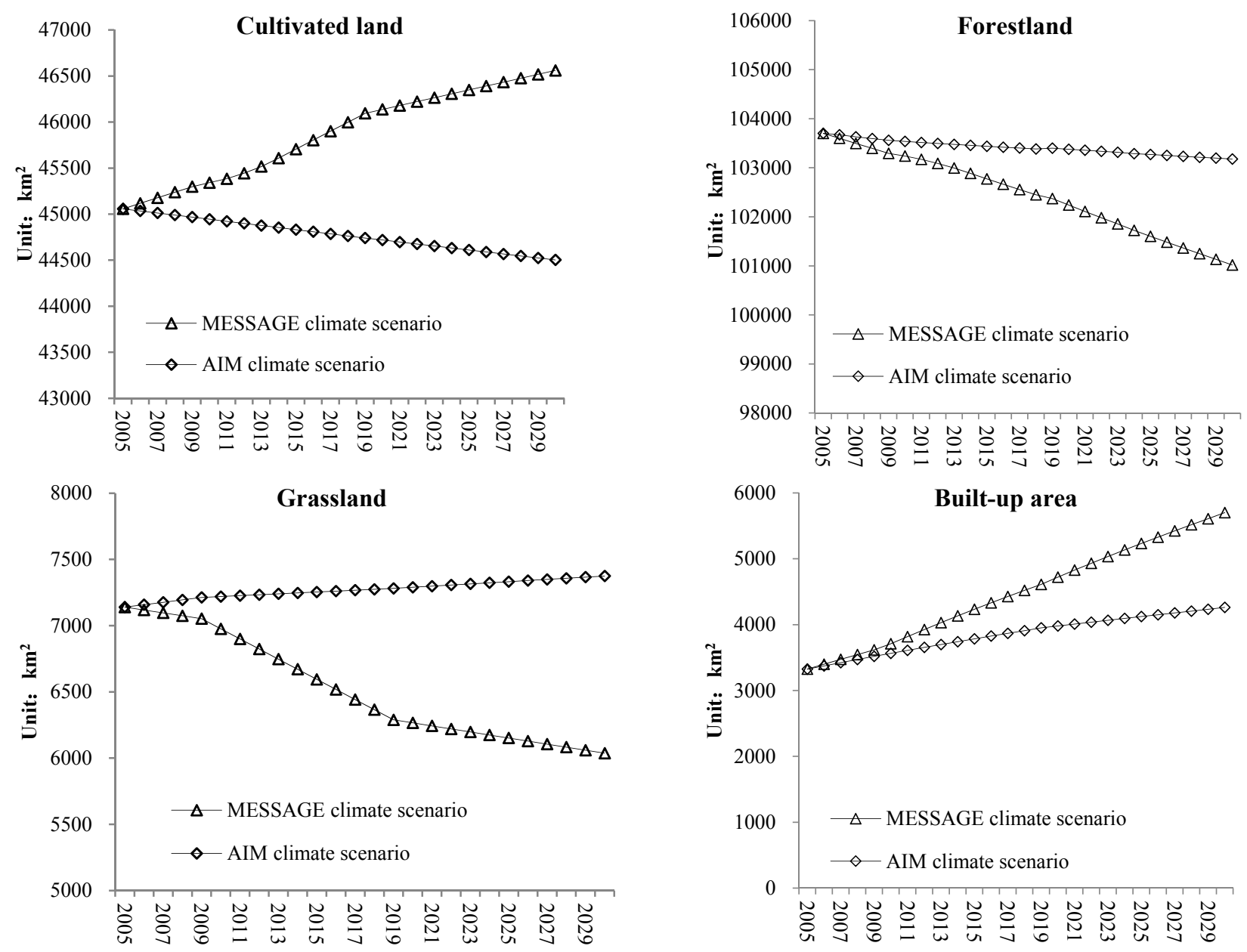

Figure 3. Land use structure under the climate scenario. AIM: Asia-Pacific integrated model; MESSAGE: model for energy supply strategy alternatives and their general environmental impact. 


\subsubsection{Asia-Pacific Integrated Model (AIM) Climate Scenario}

The AIM model, also known as the Asia-Pacific integrated model, is a medium-high RCP scenario (RCP6) that is similar to the GCM model (RCP4.5). However, the atmospheric radiation intensity under the AIM climate scenario is $6 \mathrm{~W} \cdot \mathrm{m}^{-2}$, which means that the world will not make all efforts to achieve a positive greenhouse gas reduction target. Under the AIM climate scenario, the range of the four land use types is smaller than those under the MESSAGE climate scenario, which suggests that the development rate is relatively slow and that land use change is not as significant as under the MESSAGE climate scenario (Figure 3).

Specifically, cultivated land decreases gradually, with an annual rate of reduction decreasing from $0.13 \%$ to $0.09 \%$. Forestland also has a decreasing trend, but according to the annual sequence analysis, the reduction rate is relatively small and close to zero. In contrast to forestland, grassland increases with a very slow rate. Compared with 2005 , the grassland increases by only $3.3 \%$ by 2030 . The built-up areas also grow slowly, with the growth rate being $28.2 \%$ from 2005 to 2030, which is far less than that of the MESSAGE climate scenario. The results are different from other regions under the same scenario, and the probable reason is that the research assumes that deforestation and afforestation areas, which act as the main regions for restoring the environment, slow down the development rate [25-29].

\section{Driving Mechanisms of the Deforestation and Afforestation Processes}

\subsection{Driving Mechanism for Density Variation of Forestland}

By setting up a model for the driving mechanisms of the variations in forestland density, this research estimated the influence coefficients of the factors that influence deforestation and afforestation (Table 2).

Table 2. Driving mechanism analysis of the density variation of forestland.

\begin{tabular}{|c|c|c|c|c|c|c|c|}
\hline \multicolumn{8}{|c|}{$Y$ : Density Variation of Forestland } \\
\hline$X$ & Equation (1) & Equation (2) & Equation (3) & Equation (4) & Equation (5) & Equation (6) & Equation (7) \\
\hline $\ln ($ popden$)$ & $\begin{array}{c}-0.427 \\
(8.53) * * *\end{array}$ & $\begin{array}{c}-0.335 \\
(6.72) * * *\end{array}$ & $\begin{array}{c}-0.132 \\
(3.84) * * *\end{array}$ & $\begin{array}{c}-0.131 \\
(3.81) * * *\end{array}$ & $\begin{array}{c}-0.113 \\
(3.35) * * *\end{array}$ & $\begin{array}{c}-0.165 \\
(4.65) * * *\end{array}$ & $\begin{array}{c}-0.151 \\
(4.16) * * *\end{array}$ \\
\hline $\ln \left(g d p \_t 1\right)$ & $\begin{array}{c}0.069 \\
(1.70)^{*}\end{array}$ & $\begin{array}{l}0.039 \\
(0.98)\end{array}$ & $\begin{array}{c}-0.032 \\
(1.31)\end{array}$ & $\begin{array}{c}-0.032 \\
(1.34)\end{array}$ & $\begin{array}{c}-0.039 \\
(1.64)\end{array}$ & $\begin{array}{c}-0.031 \\
(1.25)\end{array}$ & $\begin{array}{c}-0.041 \\
(1.51)\end{array}$ \\
\hline $\ln \left(f e \_\right.$prod_t 1$)$ & - & $\begin{array}{c}0.172 \\
(4.59) * * *\end{array}$ & $\begin{array}{l}0.033 \\
(1.40)\end{array}$ & $\begin{array}{l}0.034 \\
(1.44)\end{array}$ & $\begin{array}{l}0.026 \\
(1.08)\end{array}$ & $\begin{array}{l}0.009 \\
(0.41)\end{array}$ & $\begin{array}{l}0.019 \\
(0.68)\end{array}$ \\
\hline $\ln \left(f e \_g d p \_t 1\right)$ & - & $\begin{array}{l}-0.026 \\
(0.65)\end{array}$ & $\begin{array}{l}0.002 \\
(0.09)\end{array}$ & $\begin{array}{l}0.001 \\
(0.05)\end{array}$ & $\begin{array}{l}0.002 \\
(0.06)\end{array}$ & $\begin{array}{l}0.002 \\
(0.08)\end{array}$ & $\begin{array}{l}-0.026 \\
(0.67)\end{array}$ \\
\hline $\ln (d e m)$ & - & - & $\begin{array}{c}3.325 \\
(9.65) * * *\end{array}$ & $\begin{array}{c}3.237 \\
(9.11) * * *\end{array}$ & $\begin{array}{c}2.620 \\
(6.51)^{* * *}\end{array}$ & $\begin{array}{c}2.008 \\
(4.69) * * *\end{array}$ & $\begin{array}{c}2.073 \\
(4.83) * * *\end{array}$ \\
\hline $\begin{array}{l}\text { Quadratic term } \\
\text { of } \ln (\text { dem })\end{array}$ & - & - & $\begin{array}{c}-0.298 \\
(9.74) * * *\end{array}$ & $\begin{array}{c}-0.292 \\
(9.33) * * *\end{array}$ & $\begin{array}{c}-0.244 \\
(6.99) * * *\end{array}$ & $\begin{array}{c}-0.201 \\
(5.32) * * *\end{array}$ & $\begin{array}{c}-0.206 \\
(5.45) * * *\end{array}$ \\
\hline $\ln ($ slope $)$ & - & - & $\begin{array}{c}0.169 \\
(2.25) * *\end{array}$ & $\begin{array}{c}0.185 \\
(2.41) * *\end{array}$ & $\begin{array}{c}0.376 \\
(3.86) * * *\end{array}$ & $\begin{array}{c}0.485 \\
(5.07) * * *\end{array}$ & $\begin{array}{c}0.488 \\
(5.08) * * *\end{array}$ \\
\hline $\ln ($ organic $)$ & - & - & - & $\begin{array}{l}0.158 \\
(1.00)\end{array}$ & $\begin{array}{l}0.013 \\
(0.08)\end{array}$ & $\begin{array}{c}-0.064 \\
(0.42)\end{array}$ & $\begin{array}{c}-0.052 \\
(0.34)\end{array}$ \\
\hline $\ln (p a)$ & - & - & - & - & $\begin{array}{l}61.772 \\
(1.14) \\
\end{array}$ & $\begin{array}{l}107.324 \\
(1.95) *\end{array}$ & $\begin{array}{c}98.469 \\
(1.79) *\end{array}$ \\
\hline
\end{tabular}


Table 2. Cont.

\begin{tabular}{|c|c|c|c|c|c|c|c|}
\hline \multicolumn{8}{|c|}{$Y:$ Density Variation of Forestland } \\
\hline$x$ & Equation (1) & Equation (2) & Equation (3) & Equation (4) & Equation (5) & Equation (6) & Equation (7) \\
\hline $\begin{array}{c}\text { Quadratic term } \\
\text { of } \ln (p a)\end{array}$ & - & - & - & - & $\begin{array}{c}-4.083 \\
(1.12)\end{array}$ & $\begin{array}{l}-7.164 \\
(1.92) *\end{array}$ & $\begin{array}{l}-6.578 \\
(1.76) *\end{array}$ \\
\hline $\ln (t a)$ & - & - & - & - & $\begin{array}{l}646.107 \\
(2.29) * *\end{array}$ & $\begin{array}{l}634.687 \\
(2.20) * *\end{array}$ & $\begin{array}{c}697.959 \\
(2.41) * *\end{array}$ \\
\hline $\begin{array}{c}\text { Quadratic term } \\
\text { of } \ln (t a)\end{array}$ & - & - & - & - & $\begin{array}{c}-6.393 \\
(2.23) * *\end{array}$ & $\begin{array}{c}-6.433 \\
(2.19) * *\end{array}$ & $\begin{array}{l}-7.097 \\
(2.40) * *\end{array}$ \\
\hline $\ln ($ road_den $)$ & - & - & - & - & - & $\begin{array}{c}-0.009 \\
(0.71)\end{array}$ & $\begin{array}{c}-0.009 \\
(0.65)\end{array}$ \\
\hline $\ln (d 2 p v c p)$ & - & - & - & - & - & $\begin{array}{c}0.132 \\
(2.40) * *\end{array}$ & $\begin{array}{c}0.140 \\
(2.52) * *\end{array}$ \\
\hline $\ln (d 2$ road $)$ & - & - & - & - & - & $\begin{array}{c}0.196 \\
(3.75)^{* * *}\end{array}$ & $\begin{array}{c}0.192 \\
(3.66)^{* * *}\end{array}$ \\
\hline Grain & - & - & - & - & - & - & $\begin{array}{c}0.072 \\
(1.74) *\end{array}$ \\
\hline Mng & - & - & - & - & - & - & $0.062(0.87)$ \\
\hline Constant & $\begin{array}{c}10.171 \\
(17.59) * * *\end{array}$ & $\begin{array}{c}9.803 \\
(15.38) * * *\end{array}$ & $\begin{array}{c}-1.058 \\
(1.10)\end{array}$ & $\begin{array}{l}-1.006 \\
(1.04)\end{array}$ & $\begin{array}{c}-3,844.751 \\
(2.39) * *\end{array}$ & $\begin{array}{c}-3,946.200 \\
(2.39) * *\end{array}$ & $\begin{array}{c}-4,265.844 \\
(2.56) * *\end{array}$ \\
\hline$R^{2}$ & 0.24 & 0.32 & 0.75 & 0.76 & 0.77 & 0.80 & 0.80 \\
\hline
\end{tabular}

Absolute value of $t$ statistics in parentheses * significant at $10 \%$; * significant at $5 \%$; ** significant at $1 \%$.

\subsubsection{Influence of Human Activities}

Human activities are the controlling factors for the density of forestland. This research analyzes the influencing degree of human activities by using the population density. In the regions where there is a higher population density, the damage to forest ecological systems will increase; therefore, forest density will decrease. Those negative effects slow down when other factors are involved, and the elastic coefficients also correspondingly change from -0.427 to -0.151 , and their significance are at the $1 \%$ level. It indicates that the density of forestland would decrease by $1.51 \%$ when annual population density decreases by $10 \%$; therefore, human activity must be taken into account when protecting forestland.

\subsubsection{Influence of Forestry Economy}

In theory, the development of forestry economy is closely related to the forest density, whereas it is different in this region. No matter what, the economic development or forestry production has no apparent influence on forest density. The timber output lags by two years and the gross value of forest lags are not in direct proportion to forest density, indicating that reservation of forestland is not a priority, whereas variables such as transportation and population, play more significant roles. Those results also cause the centralization of cutting and the slow restoration of primary forest, and the forestry ecological system is therefore damaged gradually. 


\subsubsection{Influence of the Natural Environment}

The natural environment is a governing factor in forestry protection and forestland area changes. The estimation illustrates that elevation and gradient prominently restrict the forest growth and forestland density. Forests are widely distributed in the regions with higher elevations and steeper slope, which means that forest density is also higher in those areas. The elastic coefficients for elevation and gradient are 2.073 and 0.488 , respectively, signifying that forestland density will increase by $20.73 \%$ and $4.88 \%$, respectively, with every $10 \%$ increase in elevation and gradient. However, when the altitude surpasses a certain height, the further development of forestry growth would be held back and the density of forestland would be somewhat decreased. Weather conditions also exert an appreciable influence on forestry growth, and linear and nonlinear relationships exist between temperature, precipitation, and forestland density. Forestland density increases with increasing annual temperature and precipitation, but it will decline when these two factors reach a certain level.

\subsubsection{Influence of Location and Transportation}

Location and transportation are also the major factors that affect forestry density. The distance to the provincial capital and to the main roads reflects the distance to human activities. The results illustrate that the nearer the forestland is to the provincial capital, the lower the density will be. The elastic coefficient is 0.140 , and its significance is at the $5 \%$ level. The elastic coefficient for the distance to main roads is 0.192 with a significance level of $1 \%$. A negative influence between forestland density and transportation density exists but is not obvious. This may be ascribed to most of the deforestation and afforestation areas located in mountainous regions, and a lagged economy with a transportation density smaller than other areas. Under such a situation, the influence of the location and transportation may not be so prominent.

\subsubsection{Influence of National Policies}

In this section, mainly the Financial Regulations for State-owned Forest Farms and Nursery Systems are considered, but the results show that the relationships between the implementations of these regulations and the forestland density are not close. Whether it is a major grain-producing area is also taken into account. The results indicate that this has a positive effect on forestland density. Those areas provide advantageous conditions with excellent soil and climate quality, which spurs the development of not only agriculture but also the forestland expansion.

\subsection{Driving Mechanisms of the Afforestation Process}

\subsubsection{Influence of Population Size}

Population size is one prominent factor that influences the conversion from other land use types to forestland. It is mainly cultivated land, grassland, and some unused land that are converted into forestland in the typical deforestation and afforestation area. In areas with higher population densities, such as urban areas, the cultivated land around them is usually converted into built-up areas, and the remaining land is utilized to grow vegetables, meeting the needs of city dwellers. In this situation, 
comparatively less land can be converted into forestland. The elastic coefficient of population density is -0.877 , indicating that converted forestland area decreases $8.77 \%$ for every $10 \%$ increase in population density (Table 3 ). In the regions with large agricultural populations, it promotes the conversion from other land use types to forestland to some extent, which means that some of the agricultural population separates itself from agriculture and turns to other fields, such as forestry, stock raising, and fishing, becoming less heavily dependent on agriculture and increasing income at the same time.

Table 3. Driving mechanism analysis of the afforestation process.

\begin{tabular}{|c|c|c|c|c|c|}
\hline \multicolumn{6}{|c|}{$Y:$ Area of other land converted to forestland } \\
\hline$X$ & Equation (1) & Equation (2) & Equation (3) & Equation (4) & Equation (5) \\
\hline $\ln ($ popden $)$ & $\begin{array}{c}-0.876 \\
(17.84) * * *\end{array}$ & $\begin{array}{c}-0.841 \\
(17.25) * * *\end{array}$ & $\begin{array}{c}-0.828 \\
(16.81)^{* * *}\end{array}$ & $\begin{array}{c}-0.817 \\
(16.49) * * *\end{array}$ & $\begin{array}{c}-0.786 \\
(16.63) * * *\end{array}$ \\
\hline $\ln ($ agrpop $)$ & $\begin{array}{c}0.686 \\
(13.16) * * *\end{array}$ & $\begin{array}{c}0.692 \\
(15.92) * * *\end{array}$ & $\begin{array}{c}0.670 \\
(15.03)^{* * *}\end{array}$ & $\begin{array}{c}0.664 \\
(14.87) * * *\end{array}$ & $\begin{array}{c}0.694 \\
(16.26) * * *\end{array}$ \\
\hline $\ln (g d p)$ & $\begin{array}{c}-0.138 \\
(2.77) * * *\end{array}$ & $\begin{array}{c}-0.185 \\
(4.41) * * *\end{array}$ & $\begin{array}{c}-0.191 \\
(4.67) * * *\end{array}$ & $\begin{array}{c}-0.185 \\
(4.54) * * *\end{array}$ & $\begin{array}{c}-0.117 \\
(2.89) * * *\end{array}$ \\
\hline $\ln \left(f e \_p r o d \_t 1\right)$ & - & $\begin{array}{l}0.023 \\
(0.73)\end{array}$ & $\begin{array}{l}0.051 \\
(1.59)\end{array}$ & $\begin{array}{l}0.046 \\
(1.39)\end{array}$ & $\begin{array}{l}0.072 \\
(0.28)\end{array}$ \\
\hline $\ln \left(f e \_g d p \_t 1\right)$ & - & $\begin{array}{c}0.088 \\
(2.77) * * *\end{array}$ & $\begin{array}{c}0.094 \\
(3.07) * * *\end{array}$ & $\begin{array}{c}0.091 \\
(2.96) * * *\end{array}$ & $\begin{array}{c}0.154 \\
(4.89) * * *\end{array}$ \\
\hline $\ln (Y)$ & - & $\begin{array}{c}2.565 \\
(8.40) * * *\end{array}$ & $\begin{array}{c}2.390 \\
(8.04) * * *\end{array}$ & $\begin{array}{c}2.319 \\
(7.67) * * *\end{array}$ & $\begin{array}{c}2.277 \\
(7.94) * * *\end{array}$ \\
\hline Quadratic term of $\ln (Y)$ & - & $\begin{array}{c}-0.151 \\
(7.10) * * *\end{array}$ & $\begin{array}{c}-0.139 \\
(6.75) * * *\end{array}$ & $\begin{array}{c}-0.133 \\
(6.29) * * *\end{array}$ & $\begin{array}{c}-0.130 \\
(6.47) * * *\end{array}$ \\
\hline $\ln (t a)$ & - & - & $\begin{array}{r}-1,640.635 \\
(4.57) * * *\end{array}$ & $\begin{array}{c}-1,669.297 \\
(4.40) * * *\end{array}$ & $\begin{array}{c}-1,577.328 \\
(4.38) * * *\end{array}$ \\
\hline Quadratic term of $\ln (t a)$ & - & - & $\begin{array}{c}16.660 \\
(4.56) * * *\end{array}$ & $\begin{array}{c}16.953 \\
(4.39) * * *\end{array}$ & $\begin{array}{c}16.019 \\
(4.37) * * *\end{array}$ \\
\hline $\ln (p a)$ & - & - & - & $\begin{array}{l}130.855 \\
(1.81)^{*}\end{array}$ & $\begin{array}{c}140.178 \\
(2.04) * *\end{array}$ \\
\hline Quadratic term of $\ln (p a)$ & - & - & - & $\begin{array}{l}-8.854 \\
(1.81)^{*}\end{array}$ & $\begin{array}{c}-9.478 \\
(2.04) * *\end{array}$ \\
\hline$T g h l$ & - & - & - & - & $\begin{array}{c}0.285 \\
(5.43) * * *\end{array}$ \\
\hline Constant & $\begin{array}{c}-4.032 \\
(7.27) * * *\end{array}$ & $\begin{array}{c}-14.473 \\
(11.90) * * *\end{array}$ & $\begin{array}{l}9,154.924 \\
(4.56) * * *\end{array}$ & $\begin{array}{l}8,831.888 \\
(4.12) * * *\end{array}$ & $\begin{array}{l}8,283.760 \\
(4.07) * * *\end{array}$ \\
\hline$R^{2}$ & 0.69 & 0.78 & 0.79 & 0.80 & 0.82 \\
\hline
\end{tabular}

Absolute value of $\mathrm{t}$ statistics in parentheses. $*$ significant at $10 \% ; * *$ significant at $5 \% ; * * *$ significant at $1 \%$.

\subsubsection{Influence of Social Economy}

The development of economy also restricts conversion from other types of land use to forestland to a certain degree. The coefficient is -0.117 , and the significance is at the $1 \%$ level, manifesting in the conversion being held back in areas with higher total output values. In contrast, the forestry output value has a positive influence on the conversion, and the elastic coefficient ranges from 0.088 to 0.154 , 
with significance at the $1 \%$ level (Table 3). This result is explained by the transfer of the labor force to this area, and it promotes the development of forestry. Timber output exerts little influence on conversion, revealing a problem: attention is not paid to ensuring the sustainable development of forests at the time of exploitation. The linear and nonlinear relationships between forest density and conversion illustrate that the conversion area also increases with increasing forestry density, but once a certain level is surpassed, further development will be hindered.

\subsubsection{Influence of Climate}

Climate is also an influencing factor. The research results state that in areas with higher temperature, the conversion from other types to forestland is relatively low. However, in areas with higher rainfall, the conversion area is larger. The nonlinear elastic coefficients for temperature and average annual precipitation are 16.019 and -9.478 , respectively, which are opposite in sign to the linear elastic coefficients (Table 3). This result also suggests that the relationship between climate and conversion is not merely linear.

\subsubsection{Influence of National Policy}

The Grain for Green Project is beneficial to conversion. The elastic coefficient is 0.285 , and the significance is at the $1 \%$ level, which demonstrates the validity of this policy. The allowance for the farmers continues to reinforce the efforts to convert cultivated land to ecological forests, ensuring the safety of forestry ecosystems.

\subsection{Driving Mechanism of the Deforestation Process}

\subsubsection{Influence of Population Size}

Population size plays a decisive role in forest degradation. In densely populated areas, forest degradation is not severe, whereas in areas with large agricultural population, forest degradation intensifies. The results illustrate that the forest degradation in this area, rather than being influenced by urbanization and expansion of construction needs, is actually aggravated by the expansion of the agricultural population. Furthermore, in places where there is a large population size, the forestry area is small, and in areas with large agricultural population, it is a densely forested area in most cases. With the involvement of other factors, the population size coefficient for forest degradation changes from -1.731 to -1.004 (significance at the $1 \%$ level), whereas the influence coefficient of the agricultural population for forest degradation decreases from 2.039 to 1.318 (significance at the $1 \%$ level) (Table 4).

\subsubsection{Influence of Social Economy}

The development of non-agricultural economy drives forest degradation and promotes the conversion from forestland to other types of land use. The elastic coefficient is 0.161 , implying that forestland will degenerate by $1.61 \%$ with every $10 \%$ increase in the non-agricultural economy. Forestry production is another factor promoting forest degradation. With every $10 \%$ increase in forest production, the conversion from forestland to other types will increase by $1.04 \%$. On this basis, 
attention must be paid to the cultivation of seeding to ensure the sustainable development of forestland in the process of lumbering. In areas where the economy relies not on timber production but on other forestry production, the increase in the total forestry output value imposes restrictions on the conversion, with an influence coefficient of -0.136 (Table 4). Linear relationships between forest density and forest degradation indicate that in areas with higher forest densities, the degradation area is smaller, which is a noteworthy phenomenon. After environmental problems become exacerbated, the restorability and sustainability of an ecosystem can never be realized.

Table 4. Driving mechanism analysis of the deforestation process.

\begin{tabular}{|c|c|c|c|c|c|c|c|}
\hline \multicolumn{8}{|c|}{$Y$ : Area of Forestland Converted to Other Land } \\
\hline$X$ & Equation (1) & Equation (2) & Equation (3) & Equation (4) & Equation (5) & Equation (6) & Equation (7) \\
\hline $\ln (p o p)$ & $\begin{array}{c}-1.731 \\
(6.24) * * *\end{array}$ & $\begin{array}{c}-1.673 \\
(6.83) * * *\end{array}$ & $\begin{array}{c}-1.544 \\
(6.24) * * *\end{array}$ & $\begin{array}{c}-1.542 \\
(6.22) * * *\end{array}$ & $\begin{array}{c}-1.470 \\
(5.93) * * *\end{array}$ & $\begin{array}{c}-1.147 \\
(4.88) * * *\end{array}$ & $\begin{array}{c}-1.004 \\
(4.19) * * *\end{array}$ \\
\hline $\ln ($ agrpop $)$ & $\begin{array}{c}2.039 \\
(9.64) * * *\end{array}$ & $\begin{array}{c}2.045 \\
(10.94) * * *\end{array}$ & $\begin{array}{c}1.972 \\
(10.48) * * *\end{array}$ & $\begin{array}{c}1.966 \\
(10.43) * * *\end{array}$ & $\begin{array}{c}1.937 \\
(10.32) * * *\end{array}$ & $\begin{array}{c}1.445 \\
(7.59) * * *\end{array}$ & $\begin{array}{c}1.318 \\
(6.75) * * *\end{array}$ \\
\hline $\ln \left(n a g r \_g d p\right)$ & $\begin{array}{l}0.112 \\
(1.47)\end{array}$ & $\begin{array}{c}0.212 \\
(3.16) * * *\end{array}$ & $\begin{array}{c}0.173 \\
(2.55) * *\end{array}$ & $\begin{array}{c}0.174 \\
(2.56) * *\end{array}$ & $\begin{array}{c}0.168 \\
(2.49) * *\end{array}$ & $\begin{array}{c}0.193 \\
(3.15) * * *\end{array}$ & $\begin{array}{c}0.161 \\
(2.58) * *\end{array}$ \\
\hline $\ln \left(f e \_\right.$prod_t 1$)$ & - & $\begin{array}{l}0.068 \\
(1.60)\end{array}$ & $\begin{array}{c}0.081 \\
(1.89) *\end{array}$ & $\begin{array}{c}0.081 \\
(1.87)^{*}\end{array}$ & $\begin{array}{c}0.116 \\
(2.58) * *\end{array}$ & $\begin{array}{c}0.125 \\
(2.92) * * *\end{array}$ & $\begin{array}{c}0.104 \\
(2.40) * *\end{array}$ \\
\hline $\ln \left(f e \_g d p \_t 1\right)$ & - & $\begin{array}{c}-0.146 \\
(3.30) * * *\end{array}$ & $\begin{array}{c}-0.133 \\
(3.03) * * *\end{array}$ & $\begin{array}{c}-0.132 \\
(2.99) * * *\end{array}$ & $\begin{array}{c}-0.144 \\
(3.26) * * *\end{array}$ & $\begin{array}{c}-0.150 \\
(3.75) * * *\end{array}$ & $\begin{array}{c}-0.136 \\
(3.39) * * *\end{array}$ \\
\hline $\ln (y)$ & - & $\begin{array}{c}-1.253 \\
(3.28) * * *\end{array}$ & $\begin{array}{c}-0.535 \\
(1.08)\end{array}$ & $\begin{array}{r}-0.520 \\
(1.05)\end{array}$ & $\begin{array}{c}-0.745 \\
(1.48)\end{array}$ & $\begin{array}{c}-1.285 \\
(2.78) * * *\end{array}$ & $\begin{array}{c}-1.261 \\
(2.75) * * *\end{array}$ \\
\hline $\begin{array}{l}\text { Quadratic term } \\
\text { of } \ln (y)\end{array}$ & - & $\begin{array}{c}-0.042 \\
(1.61)\end{array}$ & $\begin{array}{l}0.004 \\
(0.11)\end{array}$ & $\begin{array}{l}0.005 \\
(0.15)\end{array}$ & $\begin{array}{l}-0.007 \\
(0.20)\end{array}$ & $\begin{array}{c}-0.031 \\
(0.94)\end{array}$ & $\begin{array}{c}-0.031 \\
(0.97)\end{array}$ \\
\hline $\ln (d e m)$ & - & - & $\begin{array}{c}-0.334 \\
(2.42)^{* *}\end{array}$ & $\begin{array}{c}-0.317 \\
(2.26)^{* *}\end{array}$ & $\begin{array}{l}-0.242 \\
(1.70)^{*}\end{array}$ & $\begin{array}{l}-0.095 \\
(0.67)\end{array}$ & $\begin{array}{l}-0.098 \\
(0.69)\end{array}$ \\
\hline $\ln ($ slope $)$ & - & - & $\begin{array}{c}0.361 \\
(2.70) * * *\end{array}$ & $\begin{array}{c}0.349 \\
(2.59) * *\end{array}$ & $\begin{array}{l}0.178 \\
(1.18)\end{array}$ & $\begin{array}{c}-0.044 \\
(0.31)\end{array}$ & $\begin{array}{l}-0.005 \\
(0.03)\end{array}$ \\
\hline $\ln ($ organic $)$ & - & - & - & $\begin{array}{l}-0.197 \\
(0.69)\end{array}$ & $\begin{array}{l}-0.129 \\
(0.44)\end{array}$ & $\begin{array}{l}0.293 \\
(1.08)\end{array}$ & $\begin{array}{l}0.361 \\
(1.33)\end{array}$ \\
\hline $\ln (\mathrm{pa})$ & - & - & - & - & $\begin{array}{l}0.139 \\
(0.27)\end{array}$ & $\begin{array}{c}-0.791 \\
(1.65)\end{array}$ & $\begin{array}{c}-1.156 \\
(2.33) * *\end{array}$ \\
\hline $\ln (t a)$ & - & - & - & - & $\begin{array}{l}-34.518 \\
(2.44)^{* *}\end{array}$ & $\begin{array}{c}-8.509 \\
(0.56)\end{array}$ & $\begin{array}{c}-10.391 \\
(0.68)\end{array}$ \\
\hline $\ln ($ road_den $)$ & - & - & - & - & - & $\begin{array}{c}0.081 \\
(3.49) * * *\end{array}$ & $\begin{array}{c}0.080 \\
(3.50) * * *\end{array}$ \\
\hline $\ln (d 2 p v c p)$ & - & - & - & - & - & $-0.115(1.21)$ & $-0.038(0.38)$ \\
\hline $\ln (d 2 r o a d)$ & - & - & - & - & - & $\begin{array}{c}-0.519 \\
(5.82) * * *\end{array}$ & $\begin{array}{c}-0.546 \\
(6.14) * * *\end{array}$ \\
\hline Grain & - & - & - & - & - & - & $0.137(1.95) *$ \\
\hline Poverty & - & - & - & - & - & - & $\begin{array}{c}-0.105 \\
(1.46)\end{array}$ \\
\hline Constant & $\begin{array}{l}0.660 \\
(0.68)\end{array}$ & $\begin{array}{c}-7.123 \\
(4.51) * * *\end{array}$ & $\begin{array}{c}-3.553 \\
(1.63)\end{array}$ & $\begin{array}{c}-3.363 \\
(1.53)\end{array}$ & $\begin{array}{c}189.461 \\
(2.36) * *\end{array}$ & $\begin{array}{l}45.800 \\
(0.53)\end{array}$ & $\begin{array}{l}58.774 \\
(0.68)\end{array}$ \\
\hline$R^{2}$ & 0.42 & 0.61 & 0.63 & 0.63 & 0.64 & 0.71 & 0.72 \\
\hline
\end{tabular}

Absolute value of $t$ statistics in parentheses. * significant at $10 \% ; * *$ significant at $5 \% ; * * *$ significant at $1 \%$. 


\subsubsection{Influence of Topographic Conditions}

The natural environment, especially topography, usually exerts certain influences on the formation of forestland. However, the results of this research suggest that elevation, gradient, and soil organic matter are not closely related to forest degradation. Although certain influences of elevation and gradient are correlated with forest degradation when only the population, economy, and natural elements are involved in the equation, these relationships are no longer clear due to the involvement of local conditions and policies.

\subsubsection{Influence of Location and Transportation}

Location and transportation have vital roles in forest degradation. The distance to the provincial capital and the main roads, and the density of transportation, are the deciding variables. The results show that the distance to the provincial capital is of little importance, but the distance to the main roads has a substantial effect. The nearer the forestland is to the main roads, the more severe the forest degradation will be, and the elastic coefficient is -0.546 (Table 4 ). The main contributions to this phenomenon are human influence and the convenience of transportation, which are conducive to transporting forestry products. The density of transportation and the conversion are also tightly interrelated. In areas with larger transportation densities, the conversion area is also larger. The conversion area will increase $0.8 \%$ with every $10 \%$ increase in transportation density.

\subsubsection{Influence of National Policy}

The influences of major grain-producing areas and impoverished counties are also taken into account. The results indicate that major grain-producing areas have a certain influence on forest degradation, but there are no connections between impoverished counties and degradation. The influence coefficient of major grain producing areas on forest degradation is 0.137 (significance at $10 \%$ level).

\section{Simulation of the Deforestation and Afforestation Processes}

After the mechanism analysis, the significant variables are identified, and its regression coefficients are applied in the CLUE model to simulate the process of deforestation and afforestation.

\subsection{Validation of Simulation Results}

The simulation accuracy of single land types and the overall simulation accuracy are estimated using a confusion matrix by comparing the simulation results and land use data derived from remote sensing images in 2005, and the results show that the overall simulation accuracy of the CLUE model is $75.9 \%$ (Figure $4 \mathrm{a}$ ). Analyses of single types of land use indicate that the forestland simulation has the highest accuracy of $89.0 \%$. This is mainly because the CLUE model takes the tree age issue into account; the conversion from other land or other wooded land to closed forest is difficult to achieve in 1-2 years. Statistical simulation accuracy on the county level shows that the linear coefficient between the correct simulated grid number and the total grid number of each county is 
$0.7878\left(R^{2}=0.9824\right)$, which means that there are no significant regional differences in the regions of deforestation and reforestation, as there are no appreciable deviations from the trend line (Figure $4 \mathrm{~b}$ ).

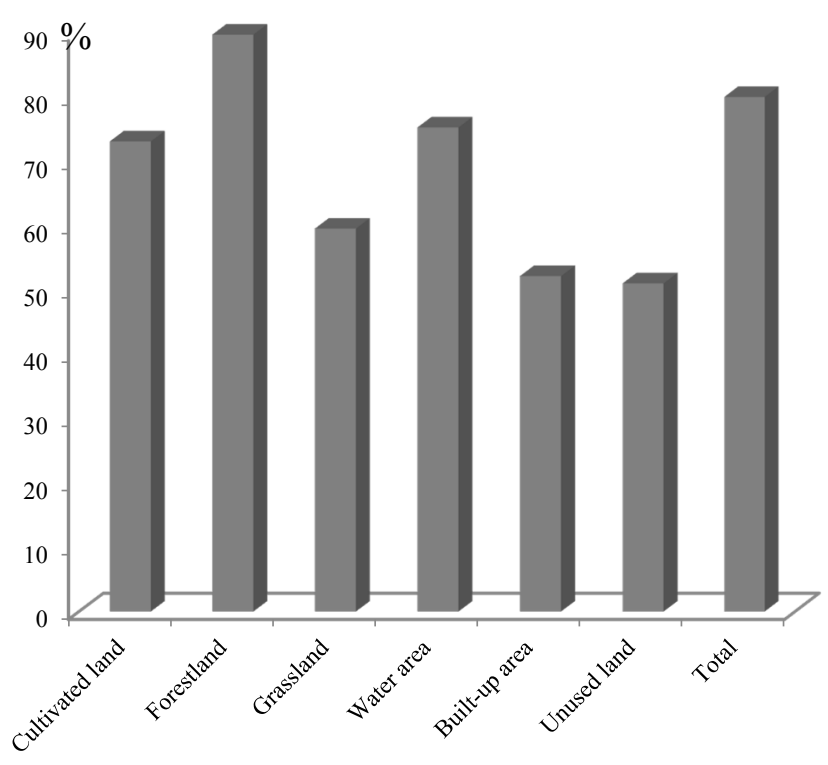

(a)

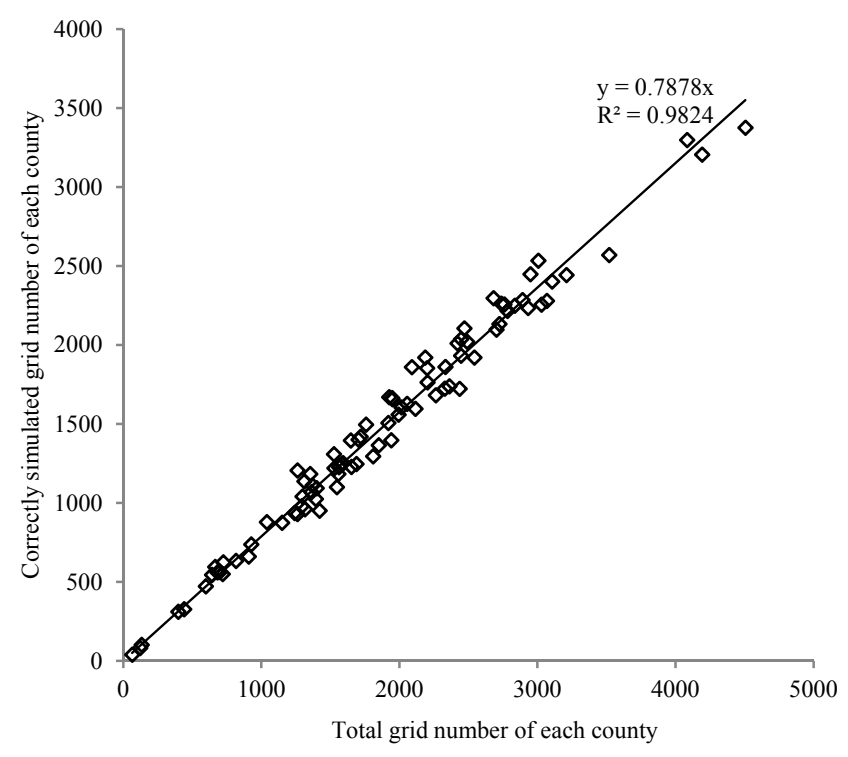

(b)

Figure 4. Accuracy verification of land use simulation: (a) Accuracy verification for each land use type; (b) accuracy verification in county level.

\subsection{Analysis of the Simulation Results under the Asia-Pacific Integrated Model (AIM)}

\section{Climate Scenario}

The dynamics of nine types of land use are simulated using the CLUE model. The results indicate that forestland area is in decline under the AIM climate scenario. During the period 2010-2020, the areas of conversion into and from forestland are $1566 \mathrm{~km}^{2}$ and $1728 \mathrm{~km}^{2}$, respectively (Figure 5). It is mainly cultivated land and grassland that are converted into forestland, and cultivated land, grassland, and portions of built-up areas are converted from forestland. Moreover, internal conversions between forest cover types also exist. The area of conversion from closed forest into shrub land and garden area is $971 \mathrm{~km}^{2}$. The regional distribution of converting out mainly resembles the provincial capital core and the area with rapid economic development. The region where the closed forest increases is mainly situated in the original forest in the south central parts. Compared with the period 2010-2020, the circumstances during the period 2020-2030 will deteriorate, with the areas of conversion into and from forestland being $1645 \mathrm{~km}^{2}$ and $1844 \mathrm{~km}^{2}$, respectively. The spatial distribution is similar to that during the period 2010-2020. Although the range during this period is not as remarkable as that under the MESSAGE climate scenario, the growth rate demands our attention. If the situation remains, catastrophe will occur in the environment. 

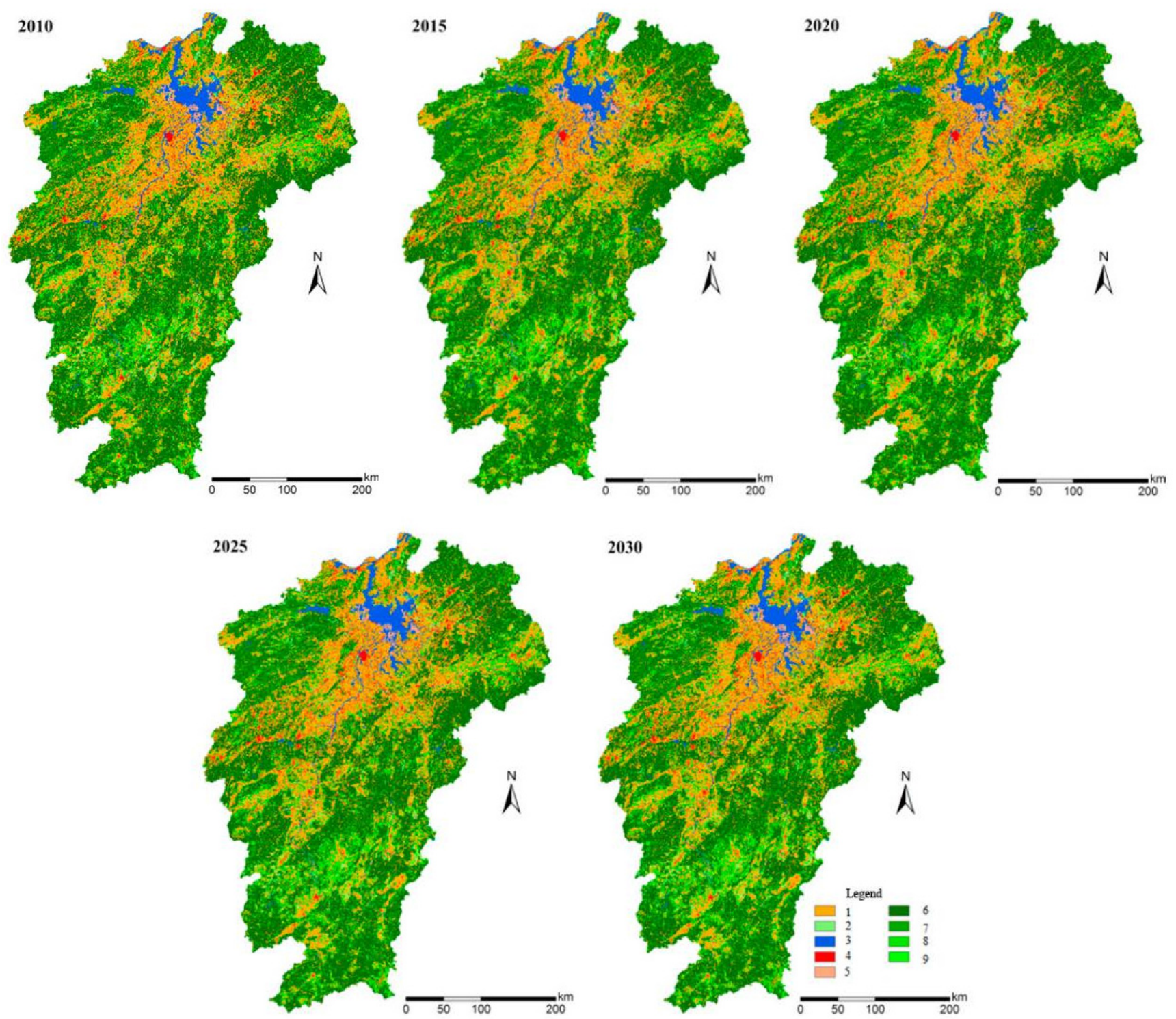

Figure 5. Spatial distribution of land use under the AIM climate scenario: (1) cultivated land; (2) grassland; (3) water area; (4) built-up area; (5) unused land; (6) closed forest; (7) open forest; (8) shrub land; and (9) garden area.

Under the AIM climate scenario, the area of decreasing closed forest reaches its maximum during the period 2020-2030 (Figure 6). The open forest area declines, but the total amount manages to remain the same. From 2020 to 2030, the area of declining open forest reaches its maximum of $467 \mathrm{~km}^{2}$. During the period 2010-2020, the area of shrub land increases to a few times that during the period 2000-2010, reaching $1492 \mathrm{~km}^{2}$, but is still inferior to the number under the AIM climate scenario during the same period. However, during the period 2020-2030, the shrub land increases to $1569 \mathrm{~km}^{2}$, outnumbering that under the MESSAGE climate scenario during the same period. Under the AIM climate scenario, the changing area of garden area remains inconspicuous, being only $74 \mathrm{~km}^{2}$ (Figure 6). Although the situation outbalances that under the MESSAGE climate scenario, certain damage remains inescapable. Approaches need to be taken to prevent closed forest from decreasing and to convert shrub land into closed forest or garden area. 


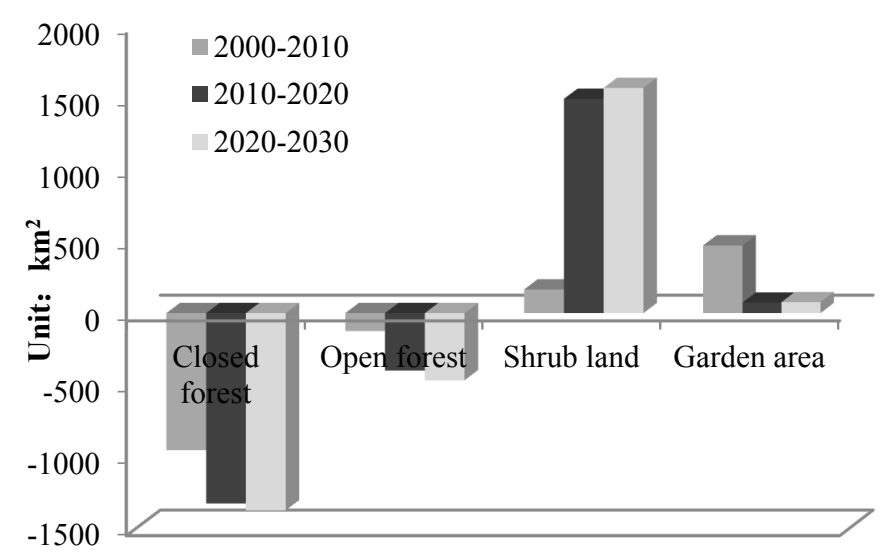

Figure 6. Forestland change under AIM climate scenario.

Under the AIM climate scenario, the range of conversion holds steady in 2010-2020 but increases during the period 2020-2030 (Figure 7).
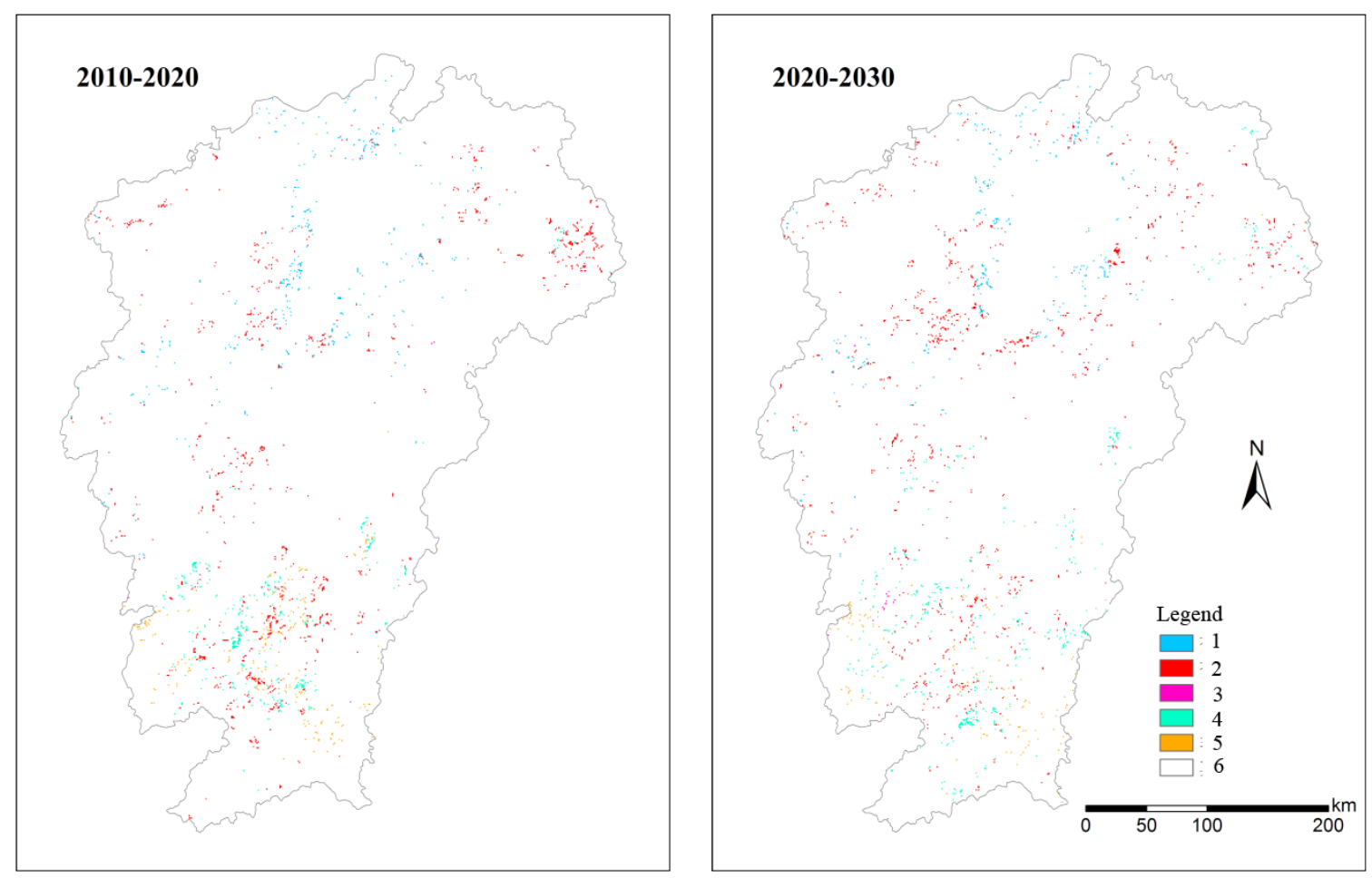

Figure 7. Conversion of forestland under the AIM climate scenario: (1) closed forest converted to non-forestland; (2) closed forest converted to other forest; (3) other forest converted to non-forestland; (4) shrub land converted to garden area; (5) non-forestland converted to forestland.

The dominating conversion type is between closed forest and non-forestland and between closed forest and other types of forest. Many types of conversion between different forestland exist but in small amounts. During the period 2010-2020, the conversion from closed forest to non-forestland will mainly be found in Jiujiang City, Nanchang City, and their surroundings. The conversion area of closed forest to other types of forest increases, involving most of the counties and cities, with northeast, 
southwest, and central areas being more centralized. In the south central parts of the deforestation and afforestation areas, the conversion from shrub land into garden area emerges as a common phenomenon. The conversion area from other types of forest to closed forest remains insignificant and is located at the border between Suichuan County and Nankang City. The conversion from non-forestland to closed forest is also found in the south central areas. During the period 2020-2030, the distribution of conversion from closed forest to non-forestland remains unaltered, with the area exceeding that during the period 2010-2020. The conversion from closed forest to other types of forest manages to continue, and in the west central and northern parts, the conversion from closed forest to other types of forest stands out. The conversion from shrub land to garden area is similar to that in 2010-2020 and centralized in the south central areas. In some counties and cities of the southwest region, non-forestland is converted into forestland but indistinctively.

\subsection{Analysis of Simulation Results under the Model for Energy Supply Strategy Alternatives and Their General Environmental Impact (MESSAGE) Climate Scenario}

The changes in the forest area under the MESSAGE climate scenario parallel the situation under the AIM climate scenario, but the type varies slightly. During the period from 2010 to 2020, the area of open forest and shrub land decreases, converted to closed forests in the southern part of the deforestation and afforestation area. In the north part, however, the forest area is lost to some extent because, as a main economic development area, conversion of land types is inevitable. However, the south part, as the main area of the original forestland, develops its economy slowly and maintains an undamaged environment, leading to an increase in forest area. In the period 2020-2030, the growth of closed forest slows down, and one of the main changes in spatial distribution is the growth of open forest, emerging mainly in the original open forest areas and developed areas of cities (Figure 8).

According to the conversion between forestland and other types of land use, a conclusion is drawn: it is mainly grassland and some parts of cultivated land that are converted to forestland, and it is mainly cultivated land and a small amount of grassland and built-up areas that are converted from forestland. During the period 2010-2020, the areas of conversion into and from forestland are $2202 \mathrm{~km}^{2}$ and $3203 \mathrm{~km}^{2}$, respectively, occupying $3.1 \%$ and $2.1 \%$ of the total forestland area. The internal conversions between forest cover types also emerge, with conversion from closed forest to other types of forest dominating, especially the conversion from closed forest and open forest to garden areas. The locations with increasing area are mainly found in the south central, northeastern, and northwestern parts of the deforestation and afforestation area, whereas the decreasing areas mainly consists of the areas with rapid economic development and areas encompassing Poyang Lake, eventually taking the shape of a triangle. During the period 2020-2030, the area of conversion into and from forestland is $1448 \mathrm{~km}^{2}$ and $2670 \mathrm{~km}^{2}$, respectively, with the variation trend slowing down.

The simulation results of different types of forest at various times demonstrate that closed forest and open forest are losing territory, and shrub land and garden area are gaining territory. The range of increase varies with time (Figure 9). In the period 2010-2020, the reduction in closed forest area reaches its maximum of $2658 \mathrm{~km}^{2}$. The reduction range decreases in the following years but is still larger than that in the period 2000-2010. Open forest is also declining, and the reduction area reaches its maximum during the period 2020 to $2030\left(715 \mathrm{~km}^{2}\right)$. The increase in shrub land reaches a 
maximum in the period 2010-2020, reaching $2036 \mathrm{~km}^{2}$, but the growth rate slows down during the next ten-year period. Garden area is increasing, but with a slow rate, with barely $102 \mathrm{~km}^{2}$ in the period 2020-2030. Those results suggest that, with decreasing forest area, closed forest being converted into shrub land, and deteriorating forest quality, the environment is in imminent danger under such a climate scenario. It is well known that forests, as the main carbon sink, play an irreplaceable role in maintaining a favorable environment. When global warming is on the rise, such a climate will definitely aggravate the situation, and the consequences will be beyond measure. Thus, efforts must be undertaken to avert this from happening and to protect the sustainable development of the environment.
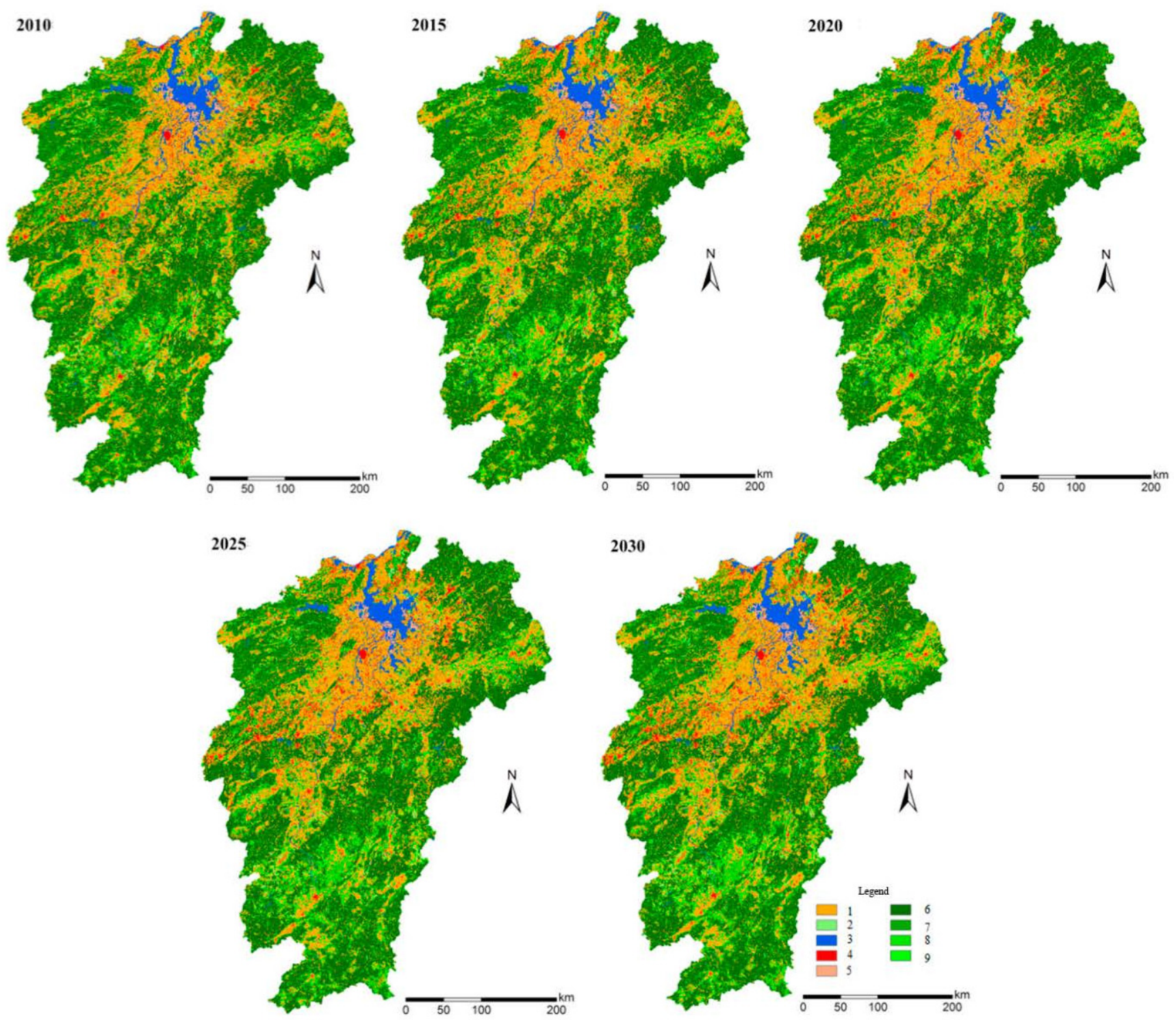

Figure 8. Spatial distribution of land use under the MESSAGE climate scenario: (1) cultivated land; (2) grassland; (3) water area; (4) built-up area; (5) unused land; (6) closed forest; (7) open forest; (8) shrub land; and (9) garden area. 


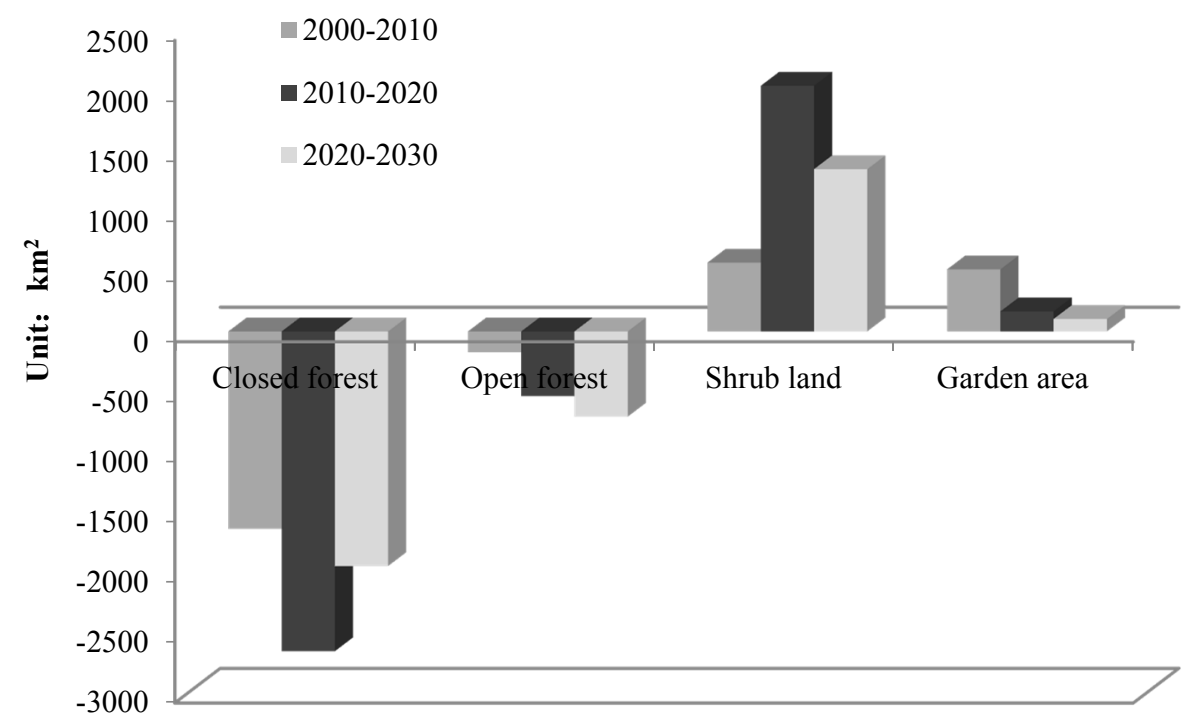

Figure 9. Forestland change under the MESSAGE climate scenario.

Under the MESSAGE climate scenario, the forestland area decreases with time going. The major conversion types are from closed forest to non-forestland, from closed forest to other types of forest, from non-forestland to closed forest, and from other types of forest to non-forestland (Figure 10).
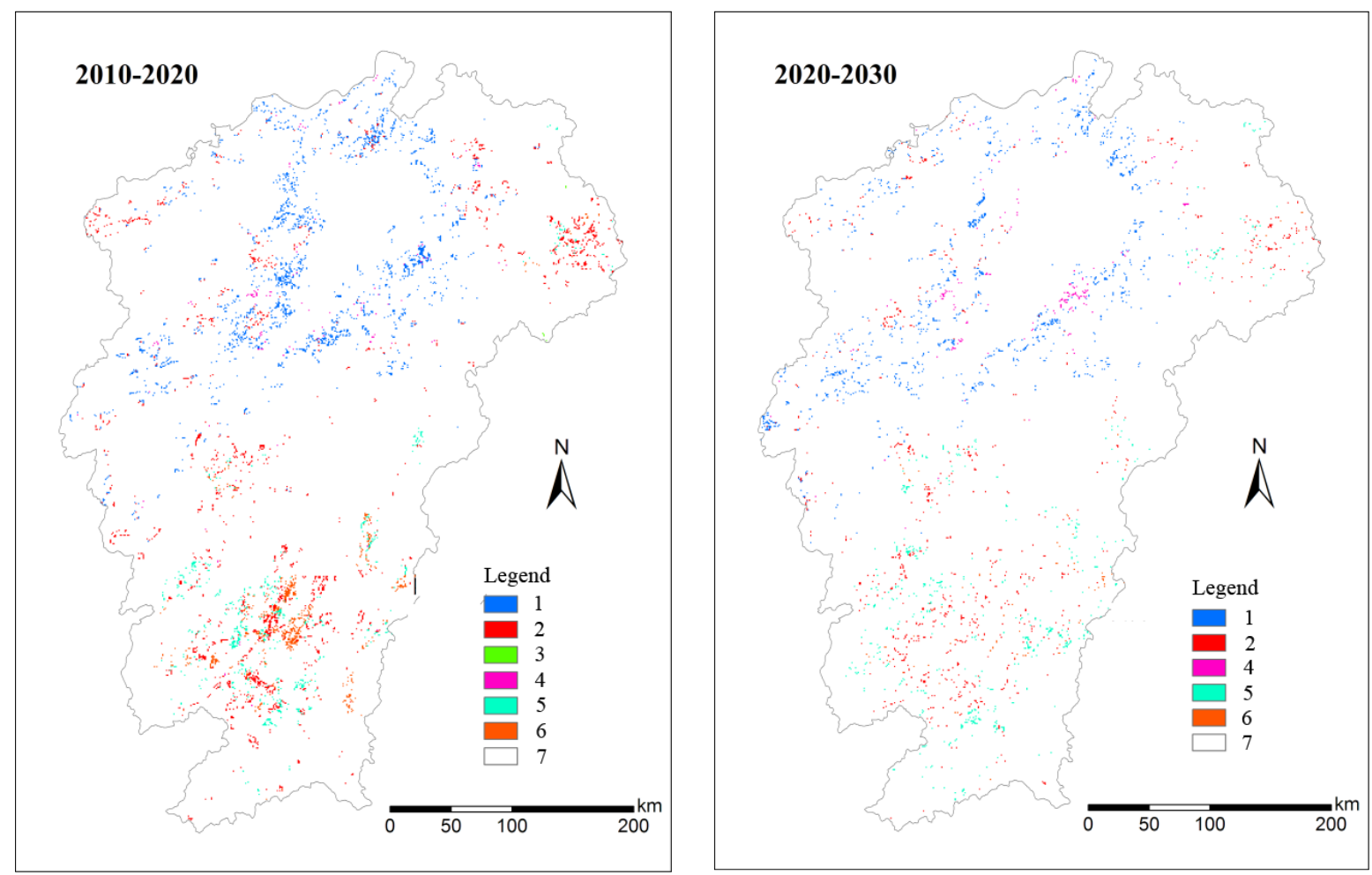

Figure 10. Conversion of forestland under the MESSAGE climate scenario: (1) closed forest converted to non-forestland; (2) closed forest converted to other forest; (3) other forest converted to closed forest; (4) other forest converted to non-forestland; (5) shrub land converted to garden area; and (6) non-forestland converted to forest. 
Conversion processes have a regional characteristic, which probably results from certain policies or an identical driving element. In the period 2010-2020, the conversion from closed forest to non-forestland mainly occurs in Jiujiang City and Nanchang City, which are in the northern part. As a border zone between forestland and cultivated land, this region is vulnerable to human activities and ecologically sensitive. The conversion from closed forest to other types of forest mainly lies in the northeast and south central parts of the deforestation and afforestation area. The conversion from other types of forest to non-forestland clusters in the regions where closed forest is converted to non-forestland. The distribution indicates that, in addition to closed forest, other forest types are also exploited in these regions. The conversion from shrub land to garden area is mainly located in the south central part, including Ganzhou City and some counties around it, and the south central part also comprises the main afforestation area, most likely because the increase in orchards converts the shrub land, grassland, and some unused land into orchards and economic forest, realizing diversified development of agriculture and transferring some of the agricultural labor force to non-agricultural roles. In the period 2020-2030, the situation remains basically the same as that in the period 2010-2020, with only slight differences. The region with the conversion from shrub land to garden area moves eastward and southward, most likely due to regional extension. The conversion from closed forest to other types of forest is sparsely distributed, but the number declines dramatically, and the situation of large area conversion remains unusual.

\section{Conclusions and Discussion}

There are three types of forestland change in the study area, i.e., forestry density fluctuation, conversion from other land use types to forestland, and conversion from forestland to other land use types, and coefficients of influencing factors on forestland change were estimated with a model of the driving mechanisms for change in forestland area. The results show that natural conditions, such as elevation and gradient, are remarkably restrictive to the forestry density. Moreover, human activities, acting as the decisive influencing factor of forestry density, have an overall negative effect on the forest density in the study area. In addition, the results reveal that forest degradation area decreases in densely populated areas and increases in areas with large agricultural population. A substantial agricultural population in the study area promotes the conversion from other land use types to forestland, while the economic development exerts a negative effect on the conversion from other types to forestland. The development of a non-agricultural economy exacerbates forest degradation, promoting the conversion from forestland to other types. Forest production development also passively aggravates forest degradation. What is more, the Grain for Green Project exerted notable positive effects on the conversion from other types to forestland.

The forestland dynamics in the study area was simulated using the CLUE model under the AIM and MESSAGE climate scenarios. The forestland area will decrease under the AIM climate scenario, which will mainly occur in economically developed areas, i.e., the regions around Poyang Lake. The lost forestland is mainly converted into grassland and cultivated land, which is found in the south central, northeastern, and northwestern parts of the study area. There will be also internal conversion of forestland, e.g., conversion from the closed forest and open forest to garden areas. Under the MESSAGE climate scenario, the forestland area also shows an overall declining trend, but in a 
moderate way. The lost forestland is mainly converted into cultivated land, grassland, and built-up areas, which mainly occurs in the regions around the provincial capital and economically developed area. However, the area of shrub land and garden land will increase, while the area of closed forest and open forest declines. There will be more cultivated land and grassland converted into forestland, which mainly occurs in the south central parts.

The simulation results of forestland dynamics are similar under the AIM and MESSAGE climate scenarios, showing similar changing trends and spatial patterns, but still with considerable differences. The MESSAGE model is a high RCP scenario with rapid economic development and more emissions, under which urban land expansion occupies a lot of cultivated land and consequently leads to more conversion of forestland to cultivated land. The deforestation will be more severe under the MESSAGE climate scenario, under which the grassland area also decreases, subsequently leading to more serious soil erosion and gradual environmental deterioration. The forestland dynamics will lead to greater pressure on local environments under the MESSAGE scenario, and therefore more efforts should be made to conserve forestland, protect the environment, and guarantee the sustainable development of social economy. By comparison, forestland also exhibits a decreasing trend under the AIM climate scenario, but the decrease of forestland is much lower than it is under the MESSAGE climate scenario, and grassland area will increase slightly. However, there is still some risk, and environmental catastrophe may occur if the situation remains unchanged.

In general, deforestation and afforestation will continue under the climate scenarios during the period 2010-2020 in the deforestation and afforestation areas due to the fact that there is still great demand for wood and other forestry products. Forestland is a material resource vital to human survival, and more measures should be carried out to protect the forestland. People's environmental awareness increases and the probability of deforestation decreases as time goes on, but to assure harmonious development between forestry production and the environmental protection, it is still of great importance to take deforestation and afforestation into account in management. Jiangxi Province is one of the few remaining forest production bases with a relatively low economic development level, which will inevitably experience rapid economic development; thus it is of great importance to protect the local forestland to ensure the sustainable development of both the forestland and economy.

\section{Acknowledgments}

This research was supported by the Major Research Plan of the National Natural Science Foundation of China (No. 91325302) and a China Postdoctoral Science Foundation funded project (No. 2014M560110). Data support from projects of the National Natural Science Foundation of China (No. 71225005) and the Exploratory Forefront Project for the Strategic Science Plan in IGSNRR, CAS are also appreciated.

\section{Author Contributions}

Qun'ou Jiang and Yuanjing Qi performed programming work, simulations and discussions, and Qun'ou Jiang wrote most sections of the manuscript. Yuwei Cheng and Qiutong Jin mainly worked on the data collection and data processing, and prepared the parameters for CLUE model. Xiangzheng Deng 
supplied guidance and provided amounts of advices for the manuscript. Chengjing Nie analyzed the equations and contributed to the discussion. All authors reviewed and polished the manuscript.

\section{Conflicts of Interest}

The authors declare no conflict of interest.

\section{References}

1. Foley, J.A.; DeFries, R.; Asner, G.P.; Barford, C.; Bonan, G.; Carpenter, S.R.; Chapin, F.S.; Coe, M.T.; Daily, G.C.; Gibbs, H.K.; et al. Global consequences of land use. Science 2005, 309, 570-574.

2. Arabatzis, G.; Christopoulou, O.; Soutsas, K. The EEC Regulation 2080/92 about forest measures in agriculture: The case of poplar plantations in Greece. Int. J. Ecodyn. 2006, 1, 245-257.

3. Liu, C.; Mullan, K.; Liu, H.; Zhu, W.; Rong, Q. The estimation of long term impacts of China's key priority forestry programs on rural household incomes. J. For. Econ. 2014, 20, 267-285.

4. Arabatzis, G.; Mattas, K. The individual and social characteristics of poplar investors-cultivators and the factors that affect the size of poplar plantations according to the EU Regulation 2080/92. Agric. Econ. Rev. 2008, 9, 86-95.

5. Arabatzis, G.; Klonaris, S. An analysis of Greek wood and wood product imports: Evidence from the linear quadratic Almost Ideal Demand System (AIDS). For. Policy Econ. 2009, 11, 266-270.

6. Zafeiriou, E.; Arabatzis, G.; Koutroumanidis, T. The fuelwood market inGreece: An empirical approach. Renew. Sustain. Energy Rev. 2011, 15, 3008-3018.

7. Kolovos, K.; Kyriakopoulos, G.; Chalikias, M. Co-evaluation of basic woodfuel types used as alternative heating sources to existing energy network. J. Environ. Prot. Ecol. 2011, 12, 733-742.

8. Chalikias, M.; Kyriakopoulos, G.; Kolovos, K.G. Environmental sustainability and financial feasibility evaluation of woodfuel biomass used for a potential replacement of conventional space heating sources. Part I: A Greek Case Study. Oper. Res. 2010, 10, 43-56.

9. Rose, S.K. Integrated assessment modeling of climate change adaptation in forestry and pasture land use: A review. Energy Econ. 2014, 46, 548-554.

10. He, J. Governing forest restoration: Local case studies of sloping land conversion program in Southwest China. For. Policy Econ. 2014, 46, 30-38.

11. Kyriakopoulos, G.; Kolovos, K.G.; Chalikias, M.S. Environmental sustainability and financial feasibility evaluation of woodfuel biomass used for a potential replacement of conventional space heating sources. Part II: A Combined Greek and the nearby Balkan Countries Case Study. Oper. Res. 2010, 10, 57-69.

12. Chen, Y.; Li, X.; Tian, Y.; Tan, M. Structural change of agricultural land use intensity and its regional disparity in China. J. Geogr. Sci. 2009, 19, 545-556.

13. Van Vuuren, D.P.; Stehfest, E.; den Elzen, M.G.J.; Kram, T.; van Vliet, J.; Deetman, S.; Isaac, M.; Goldewijk, K.K.; Hof, A.; Beltran, A.M.; et al. RCP2.6: Exploring the Possibility to Keep Global Mean Temperature Increase Below $2^{\circ} \mathrm{C}$. Clim. Chang. 2011, 109, 95-116.

14. Overmars, K.P.; Verburg, P.H.; Veldkamp, A. Comparison of a Deductive and All Inductive Approach to Specify Land Suitability in a Spatially Explicit Land Use Model. Land Use Policy 2007, 24, 584-599. 
15. Valbuena, D.; Verburg, P.H.; Bregt, A.K.; Ligtenberg, A. An agent-based approach to model land-use change at a regional scale. Landsc. Ecol. 2010, 25, 185-199.

16. Clarke, L.; Edmonds, J.; Jacoby, H.; Pitcher, H.; Reilly, J.; Richels, R. Scenarios of Greenhouse Gas Emissions and Atmospheric Concentrations; Technical Report for U.S. Climate Change Science Program: Washington, DC, USA, 2007; p. 154.

17. Sands, R.D.; Leimbach, M. Modeling agriculture and land use in an integrated assessment framework. Clim. Chang. 2003, 56, 185-210.

18. Jesper, S. Forest Tenure Reform in Asia and Africa-Local Control for Improved Livelihoods, Forest Management, and Carbon Sequestration; Bluffstone, R.A., Robinson, E.J.Z., Eds.; Resources for the Future Press: Washington, DC, USA, 2014.

19. Jagger, P.; Luckert, M.M.K.; Duchelle, A.E.; Lund, J.F.; Sunderlin, W.D. Tenure and Forest Income: Observations from a Global Study on Forests and Poverty. World Dev. 2014, 64, S43-S55.

20. Moss, R.H.; Edmonds, J.A.; Hibbard, K.A.; Manning, M.R.; Rose, S.K.; van Vuuren, D.P.; Carter, T.R.; Emori, S.; Kainuma, M.; Kram, T.; et al. The next generation of scenarios for climate change research and assessment. Nature 2010, 463, 747-756.

21. Taylor, K.E., Stouffer, R.J.; Meehl, G.A. An overview of CMIP5 and the experiment design. Bull. Am. Meteorol. Soc. 2012, 93, 485-498.

22. Van Vuuren, D.P.; Edmonds, J.; Kainuma, M.; Riahi, K.; Thomson, A.; Hibbard, K.; Hurtt, G.C.; Kram, T.; Krey, V.; Lamarque, J.F.; et al. The representative concentration pathways: An overview. Clim. Chang. 2011, 109, 5-31.

23. Meinshausen, M.; Smith, S.J.; Calvin, K.; Daniel, J.S.; Kainuma, M.L.; Lamarque, J.F.; Matsumoto, K.; Montzka, S.A.; Raper, S.C.; Riahi, K.; et al. The RCP greenhouse gas concentrations and their extensions from 1765 to 2300. Clim. Chang. 2011, 109, 213-241.

24. Ojima, D.; Emilio, M.; William, M. GLP (2005) Science Plan and Implementation Strategy; Technical Report for International Geosphere-Biosphere Program (IGBP): Stockholm, Sweden, 2005; p. 64.

25. Climate Change 2007: The Physical Science Basis; Technical Report for the Fourth Assessment of Intergovernmental Panel on Climate Change: Geneva, Switzerland, 2007.

26. Yu, R.; Wang, X.S.; Yan, Z.; Yan, H.M.; Jiang, Q.O. Regional Climate Effects of Conversion from Grassland to Forestland in Southeastern China. Adv. Meteorol. 2013, 9, doi:10.1155/2013/630953.

27. Jiang, Q.O.; Deng, X.Z.; Ke, X.L.; Zhao, C.H.; Zhang, W. Prediction and simulation of urban area expansion in Pearl River Delta Region under the RCPs climate scenarios. Chin. J. Appl. Ecol. 2014, 25, 3627-3636. (In Chinese)

28. Rindfuss, R.R.; Walsh, S.J.; Turner, B.L.; Fox, J.; Mishra, V. Developing a science of land change: Challenges and methodological issues. Proc. Natl. Acad. Sci. USA 2004, 101, 13976-13981.

29. Lambin, E.F.; Geist, H.J. Land-Use and Land-Cover Change. Local Processes and Global Impacts; Springer-Verlag: Heidelberg, Germany, 2006.

30. Verburg, P.H.; Overmars, K.P. Combining top-down and bottom-up dynamics in land use modeling: exploring the future of abandoned farmlands in Europe with the Dyna-CLUE model. Landsc. Ecol. 2009, 24, 1167-1181.

31. Verburg, P.H.; Eickhout, B.; Meijl, H.V. A multi-scale, multi-model approach for analyzing the future dynamics of European land use. Ann. Reg. Sci. 2008, 42, 57-77. 
32. Briffa, K.R. Annual climate variability in the Holocene: Interpreting the message of ancient trees. Quat. Sci. Rev. 2000, 19, 87-105.

33. Farley, K.A.; Jobbágy, E.G.; Jackson, R.B. Effects of afforestation on water yield: a global synthesis with implications for policy. Glob. Chang. Boil. 2005, 11, 1565-1576.

34. Houghton, R.A. Revised estimates of the annual net flux of carbon to the atmosphere from changes in land use and land management 1850-2000. Tellus B 2003, 55, 378-390.

35. Canadell, J.G.; le Quéré, C.; Raupach, M.R.; Field, C.B.; Buitenhuis, E.T.; Ciais, P.; Conway, T.J.; Gillett, N.P.; Houghton, R.A.; Marland, G. Contributions to accelerating atmospheric $\mathrm{CO}_{2}$ growth from economic activity, carbon intensity, and efficiency of natural sinks. Proc. Natl. Acad. Sci. USA 2007, 104, 18866-18870.

36. Donohue, R.J.; Roderick, M.L.; McVicar, T.R. On the importance of including vegetation dynamics in Budyko's hydrological model. Hydrol. Earth Syst. Sci. Discuss. 2007, 11, 983-995.

37. Odihi, J. Deforestation in afforestation priority zone in Sudano-Sahelian Nigeria. Appl. Geogr. 2003, 23, 227-259.

38. Deng, X.Z.; Huang, J.K.; Rozelle, S.; Uchida, E. Cultivated land conversion and potential agricultural productivity in China. Land Use Policy 2006, 23, 372-384.

39. Yan, D.; Schneider, U.A.; Schmid, E.; Huang, H.Q.; Pan, L.H.; Dilly, O. Impact of future climate change on land use change in Poyang Lake. Resour. Sci. 2013, 35, 2255-2265. (In Chinese)

40. Zhang, L. Impact of climate change on geographical distribution of major tree species and natural vegetation in China. Ph.D. Thesis, Chinese Academy of Forestry Science, Beijing, China, 2011. (In Chinese)

41. Jiang, D.; Hao, M.M.; Fu, J.Y.; Zhuang, D.F.; Huang, Y.H. Spatial-temporal variation of marginal land suitable for energy plants from 1990 to 2010 in China. Sci. Rep. 2014, 4, doi:10.1038/srep05816.

42. Jiang, D.; Zhuang, D.F.; Fu, J.Y.; Huang, Y.H.; Wen, K. Bioenergy potential from crop residues in China: Availability and distribution. Renew. Sustain. Energy Rev. 2012, 16, 1377-1382.

43. Ravindranath, N.H.; Somashekhar, B.S.; Gadgil, M. Carbon flow in Indian forests. Clim. Chang. 1997, 35, 297-320.

44. Masera, O.R.; Ordóñez, M.J.; Dirzo, R. Carbon emissions from Mexican forests: current situation and long-term scenarios. Clim. Chang. 1997, 35, 265-295.

45. Derek, B.; Stevenson, J.; Nelson, V. Does intensification slow crop land expansion or encourage deforestation? Glob. Food Secur. 2014, 3, 92-98.

46. Wehner, S.; Herrmann, S.; Berkhoff, K. CLUENaban-A land use change model combining social factors with physical landscape factors for a mountainous area in Southwest China. Ecol. Indic. 2014, 36, 757-765.

47. Brandt, J.S.; Butsic, V.; Schwab, B.; Kuemmerle, T.; Radeloff, V.C. The relative effectiveness of protected areas, a logging ban, and sacred areas for old-growth forest protection in southwest China. Biol. Conserv. 2015, 181, 1-8.

(C) 2015 by the authors; licensee MDPI, Basel, Switzerland. This article is an open access article distributed under the terms and conditions of the Creative Commons Attribution license (http://creativecommons.org/licenses/by/4.0/). 